\title{
The neural basis of autobiographical and semantic memory: New evidence from three PET studies
}

\author{
KIM S. GRAHAM, ANDY C. H. LEE, MATTHEW BRETT, and KARALYN PATTERSON \\ MRC Cognition and Brain Sciences Unit, Cambridge, England
}

\begin{abstract}
A novel, neuropsychologically informed paradigm (extended retrieval of events in response to a cue word) was used to investigate the neural basis of autobiographical and semantic memory. Contrasting retrieval of autobiographical memories with retrieval of semantic facts (ABM - SEM) in 24 subjects across three PET studies revealed bilateral involvement of the middle temporal gyrus (BA 21) and medial frontal cortex (BA 9/10). The opposite contrast, SEM - ABM, resulted in increased regional cerebral blood flow in left posterior temporal regions (BA 37) and left prefrontal cortex (BA 45/46). Laterality maps suggest that the bilateral pattern seen in our studies, but not often in other neuroimaging investigations, reflects the use of a task stressing retrieval of specific personal events. Further comparisons revealed that the activation in the right anterior temporal lobe during autobiographical recall was virtually identical to that seen during retrieval of information about famous people or events in contrast with retrieval of general semantic facts. These findings suggest that the retrieval of an autobiographical event requires participation from conceptual knowledge, and that this type of knowledge is bilaterally distributed in the temporal lobes.
\end{abstract}

The last few years have seen a steady increase in the number of functional neuroimaging studies aimed at investigating the neural basis of human long-term memory (LTM), especially autobiographicalmemory. In an excellent review of the autobiographical literature, Maguire (2001) summarized findings from a number of experiments-six carried out using positron emission tomography (PET) and five based on functional magnetic resonance imaging (fMRI) - and concluded that "the overall pattern across studies is of medial and left-lateralized activations" (p. 1441). Notably, however, the finding of a predominantly left-sided network of frontal and temporal regions is in stark contrast to patterns of impairment seen in neuropsychological patients: In general, it is thought that rightsided or bilateral temporal lobe lesions significantly impair retrieval of autobiographicalmemories (Conway \& Fthenaki, 2000; Kopelman \& Kapur, 2001), with selective left-sided lesions resulting in milder deficits (Eslinger, 1998; Graham, Pratt, \& Hodges, 1998; Hokkanen, Launes, Vataja, Valanne, \& Iivanainen, 1995).

\footnotetext{
We are grateful to Jon Simons and Matt Lambon Ralph for help with data collection, Marjolijn Hovius and Stefanie Hassel for rating the responses of our subjects, Adrian Owen, Marion Kellenbach, Andrew Lawrence, and John Hodges for useful discussion, and Marion Wilkinson for help with manuscript preparation. We also thank the staff at the Wolfson Brain Imaging Centre, Addenbrooke's Hospital, Cambridge, and the subjects in the study for giving so generously of their time. Correspondence concerning this article should be addressed to K. S. Graham or A. C. H. Lee, MRC Cognition and Brain Sciences Unit, 15 Chaucer Road, Cambridge CB2 2EF, England (e-mails: kim.graham@mrc-cbu. cam.ac.uk; andy.lee@mrc-cbu.cam.ac.uk).
}

The present study was designed to address this controversy, in particular by asking whether the left-sided activations documented in some functional neuroimaging studies of autobiographical memory can be attributed to the fact that subjects were not required to retrieve detailed and specific episodes from the past (Conway et al., 1999; Maguire \& Mummery, 1999; Maguire, Mummery, \& Büchel, 2000). If so, the scarcity of right temporal lobe activations in these studies may be due to a lack of autobiographical specificity rather than to a particular lateralization of this aspect of LTM to the left temporal lobe (see also Conway, Pleydell-Pearce, Whitecross, \& Sharpe, 2002, for a similar suggestion).

\section{Functional Neuroimaging Studies of Autobiographical Memory}

At the time of this writing, Maguire (2001) noted that there were 11 published functional neuroimaging studies of autobiographical memory. In 2 of these investigations (Maguire, Vargha-Khadem, \& Mishkin, 2001; Markowitsch et al., 1997), autobiographical retrieval in patients with memory impairment was studied and will not be considered further in this article, which is concerned with the neural architecture of LTM in normal subjects. We will also not discuss in detail the study by Burgess, Maguire, Spiers, and O'Keefe (2001), in which subjects navigated around a virtual-reality town meeting people and obtaining various objects. Although that investigation does tap aspects of personal event memory-subjects were later scanned while answering forced-choice questions about what objects they had received and where they had obtained them-it differs experimentally from the other pub- 
lished autobiographicalstudies and is more similar to studies involving the types of anterograde memory tasks (recall and recognition of verbal and visual stimuli after a delay) frequently adopted in neuroimaging studies of episodic memory (Fletcher \& Henson, 2001). Of the 8 remaining studies, it is notable that two experiments did not activate temporal lobe regions (Andreasen et al., 1995; Andreasen et al., 1999), which, as will be discussed in more detail below, may reflect the control conditionsused by these authors (e.g., rest or relaxation).

The remaining six papers discussed by Maguire (2001), plus two other recent papers (Markowitsch et al., 2000; Niki \& Luo, 2002), have addressed two main issues with respect to the neural basis of autobiographicalmemory: (1) whether some regions of the brain, especially the hippocampus and other medial temporal lobe regions, are more involved in the retrieval of recent memories (Conway et al., 1999; Maguire, Henson, Mummery, \& Frith, 2001; Niki \& Luo, 2002; Ryan et al., 2001), and (2) the role played by more lateral temporal and frontal regions in the retrieval of personal events (Conway et al., 1999; Fink et al., 1996; Maguire \& Mummery, 1999; Maguire et al., 2000; Markowitsch et al., 2000). Until Niki and Luo, there was relatively little evidence that hippocampal regions were more active during the retrieval of recent in comparison with remote memories (see Murre, Graham, \& Hodges, 2001; Nadel, Samsonovich, Ryan, \& Moscovitch, 2000; Nestor, Graham, Bozeat, Simons, \& Hodges, 2002; Squire, 1992 , for theoretical reviews about this issue). For example, Ryan et al. (2001) used fMRI to study the recollection of autobiographical events from two time periods (either within the last 4 years or more than 20 years ago) and found no evidence that activation levels in the hippocampus were modulated by memory age. Notably, however, Ryan et al. also did not observe more activation for remote than for recent memories, a finding that might have been predicted from the memory consolidation model of Nadel and Moscovitch (1997), in which older memories are represented by more traces in the medial temporal lobe (Nadel et al., 2000). Niki and Luo, however, report an fMRI study in which volunteers were asked to remember (or imagine) their experiences of place and landmark names that they had visited either 7 or more years ago or recently (i.e., within the last 2 years). Retrieval of the most recent memories resulted in increased activation in the medial temporal lobe, especially the left parahippocampal gyrus, even in a contrast that took into account the number of details produced by the subjects.

In terms of lateral cortical activations, the majority of these eight studies have reported a left lateralized frontal/ temporal network during the retrieval of autobiographical event memories. This network typically includes the temporal pole, the temporoparietal junction, and the medial frontal regions (Maguire \& Mummery, 1999; Maguire et al., 2000). The only major deviations from this pattern are the reports by Fink et al. (1996) and Markowitsch et al. (2000) of right temporal activations, a finding that is thought to reflect a bias toward the retrieval of affect-laden material in these studies (Conway \& Fthenaki, 2000; Maguire, Henson, et al., 2001; Markowitsch et al., 2000).

\section{Neuropsychological Investigations of Autobiographical Memory}

In the last 2 years, a number of authors have published detailed reviews of the literature on autobiographical memory and focal retrograde amnesia (Conway \& Fthenaki, 2000; Kapur, 2000; Kopelman, 2000; Kopelman \& Kapur, 2001); consequently, this section will touch on this topic only briefly. There is some evidence of dissociability between autobiographical and semantic memory, although, as will be noted below, these distinctions are not clear-cut. Whereas some patients present with selective impairment of autobiographical memory in the context of good, or even normal, semantic memory (Dalla Barba, Cipolotti, \& Denes, 1990; Evans, Breen, Antoun, \& Hodges, 1996; Kapur, Young, Bateman, \& Kennedy, 1989; Levine et al., 1998), a smaller number of patients show the opposite pattern with poor retrieval of aspects of semantic knowledge despite better recall of autobiographicalevents (De Renzi, Liotti, \& Nichelli, 1987; Kitchener \& Hodges, 1999).

In terms of the neural basis of LTM deficits, impairments to autobiographical or semantic memory are frequently associated with damage to anterior temporal lobe regions, particularly the temporal pole (Conway \& Fthenaki, 2000; Hodges \& K. S. Graham, 2001; Kitchener \& Hodges, 1999; Kroll, Markowitsch, Knight, \& von Cramon, 1997). Furthermore, there is at least some suggestion of differential left versus right temporal involvement in these two aspects of disruption to LTM. For example, Kopelman, Stanhope, and Kingsley (1999) found severe autobiographical deficits in patients with right-sided temporal lobe lesions after herpes simplex encephalitis in comparison with the deficits found in patients with left-sided damage (see also the single cases of left temporal lobe damage described by Calabrese et al., 1996, and the studies of Eslinger, 1998; Hokkanen et al., 1995; and Markowitsch et al., 1993).

Kopelman and Kapur (2001) remind us, however, that the distinction between autobiographical and semantic memory is often rather blurry; for example, patients with right temporal lobe damage frequently show deficits in remote semantic tasks (e.g., knowledge of public events and famous people), in addition to their impairments in autobiographical recall. This finding raises several unanswered questions: (1) Are different categories of semantic knowledge-in particular, knowledge of famous people versus knowledge about objects and the meanings of words-represented separately, and (2) what is the relationship between these semantic systems and autobiographical memory? These topics will be discussed in more detail later in this paper. For now, however, it is worth noting that the distinctionbetween aspects of semantic knowledge and autobiographical memory (Gorno-Tempini, Cipolotti, \& Price, 2000; GornoTempini \& Price, 2001; Gorno-Tempini, Wenman, Price, Rudge, \& Cipolotti, 2001; Kitchener \& Hodges, 1999; Kopelman et al., 1999; Maguire \& Mummery, 1999) is not 
absolute and that tests of remote memory, especially in neuropsychological studies, often require access to both semantic and personal event information.

\section{Methodological Issues}

These brief summaries illustrate a significant discrepancy between findings from functional neuroimaging and those from neuropsychology on the neural basis of autobiographical memory, with many (though not all) of the former indicating a critical role for the left temporal lobe and the latter implicating a more bilaterally distributed network. Given that it is virtually impossible to isolate the unique contributions of autobiographical and semantic memory to performance on neuropsychological tests of remote memory, whereas functional neuroimaging experiments are designed to address precisely this methodological issue, perhaps one should give greater weight to the latter technique and conclude, as does Maguire (2001) in her recent review of the literature, that autobiographical memory is dependent on a network of left frontal and temporal regions. For various reasons, however, we will argue that this assumption seems premature, in particular given that a number of methodological issues still remain to be addressed about the functional neuroimaging of autobiographical memory.

Pretesting of subjects prior to scanning. A number of the autobiographical neuroimaging studies to date have involved semistructured interviews or pretesting of stimuli with subjects prior to scanning. Although there are good reasons to carry out such interviews (see Maguire, 2001, for more details), it is not clear how this pretesting of subjects affects subsequent performance and/or patterns of blood flow in the scanner. As Maguire noted, "Does questioning subjects, even briefly, before scanning change the essential nature of the memory one wishes to examine? Is the memory now recent as opposed to what might have been a remote memory? Has the event been recoded and is that what one is scanning and not recall of the original event?" (p. 1445). In an attempt to address this difficult issue, as part of a larger experiment Ryan et al. (2001) scanned 3 subjects for whom cues about past experiences were acquired from spouses rather than from the subjects themselves. The results obtained for these 3 subjects were similar to those of the rest of the group, a finding that may partially reassure some experimenters that pretesting is not necessarily influencing the patterns of activations seen during autobiographical retrieval (see also Conway et al., 1999). Further data are needed, however, and there is no doubt that researchers interested in autobiographicalmemory would generally prefer to avoid the need for semistructured interviews prior to scanning.

Generic versus detailed recall. Four of the eight neuroimaging studies reported in the literature have used paradigms that seem unlikely to result in detailed recall of autobiographical events. The three studies by Maguire and colleagues (Maguire, 2001; Maguire \& Mummery, 1999; Maguire et al., 2000) used a yes-no statement verification task (e.g., "You did a tour of Concorde at Heathrow"), and the investigation by Conway et al. (1999), though based on a neuropsychological test of autobiographical memory (Crovitz \& Schiffman, 1974; Graham \& Hodges, 1997), did not provide subjects with sufficient time to retrieve a detailed event (the subjects were presented with a word for $200 \mathrm{msec}$ and then had 4,800 msec to recall a specific episode). Conway et al. (1999) chose this brief retrieval period for good experimental reasons, to match the temporal characteristics of their autobiographical condition to those of a paired-associate control condition; but, in pilot testing for the experiment reported here, it was notable that the control subjects rarely produced any specific details about an event during the first 4-5 sec after presentation of the target word and were typically able to discuss these events for 25-60 sec, depending on the target word (see also Conway, 2001).

Conway et al. (2002) raise a similar point with particular reference to the paradigm of Maguire (Maguire, Henson, et al., 2001; Maguire \& Mummery, 1999; Maguire et al., 2000). In these experiments, subjects completed a questionnaire about personal and public events prior to testing. Details from this questionnaire were used to create real and made-up statements, and the subjects were asked during scanning to verify whether each statement was true or false. A central assumption of this method is that the verification of the statement (e.g., "You fell out of a tree as a child") automatically brings to mind the very incident described. As Conway et al. (2002) suggest, however, it is highly plausible that accurate performance on such verification tasks may instead be based on autobiographical knowledge (see below), without access to and retrieval of the specified episodic event.

In a series of papers, Conway and colleagues (Conway, 2001; Conway \& Fthenaki, 2000; Conway \& PleydellPearce, 2000; Conway, Pleydell-Pearce, \& Whitecross, 2001; Conway et al., 2002; Conway et al., 1999) proposed that autobiographical memories are transitory representations that are effortfully constructed and maintained using different types of autobiographical knowledge (life events, general events, and sensory-perceptual episodic memoriesalso called event-specific knowledge; see Figure 1 of Conway et al., 1999). Conway (2001) notes that memories of lifetime periods (e.g., "when I was at university," "when I was in California," "when I worked in Cambridge") contain knowledge about people, activities, locations, feelings, and evaluations common to a period as a whole, which can be used to access more specific knowledge held at the level of general events, which also contains knowledge about people, activities, locations, and so on, related to more specific experiences (e.g., freshman orientation week, working with Bruce, job interview, etc.). Knowledge at the general level provides a mechanism for retrieval of a more specific and, presumably, temporally defined episodic event, and Conway argues that it is the inclusion of this sensory-perceptual episodic memoryso called because these memories are thought to be stored close to specialized posterior sensory-perceptual regionsthat gives autobiographical memory its recollective prop- 
erties (e.g., "the sense of the self in the past"; Conway, 2001, p. 1375).

This view of autobiographical retrieval entails two fundamental implications for functional neuroimaging. First, the process is unlikely to be rapid (e.g., completed within the $5 \mathrm{sec}$ provided by Conway et al., 1999). Second, the retrieval of a recollective event is not an automatic endpoint of the process; instead, individuals may rely on higher levels of knowledge (e.g., general events) to solve the task if this is all that is required (Maguire \& Mummery, 1999).

Methods of obtaining behavioral data about performance. Owing to the difficulties of having subjects speak aloud while being scanned (especially with fMRI), most of the current autobiographical memory studies have not measured autobiographicaloutput during the actual scanning event (Fink et al., 1996). For example, in Ryan et al. (2001), subjects were given life event labels, such as a family picnic and learning to drive, and were asked to think about a memory related to each category while they were being scanned. After the scanning event, the subjects were given the same cues again and asked to describe verbally the details of the memories they had recalled and to rate the memories for vividness, emotional valence, physical arousal, and importance. Given the reconstructive and transitory nature of autobiographicalmemory recall (Conway, 2001), experimenters using this technique can never be sure that the autobiographicalmemory recalled later is indeed the same event that was thought about in the scanner. A significant improvement in this area of research would be the behavioral acquisition of autobiographical memories (i.e., recorded responses from subjects) during scanning.

Control conditions. The control conditions used for comparison with autobiographical memory conditions have included rest (Andreasen et al., 1995), relaxation (Ryan et al., 2001), viewing rectangular boxes of varying pixel intensity (Conway et al., 1999), word-stem completion (Ryan et al., 2001), paired-associate memory (Conway et al., 1999), and imagining nonpersonal events (Fink et al., 1996). Although the design of control conditions in functional neuroimaging is never easy, the use of rest or relaxation conditions seems particularly troublesome. A recent neuroimaging study by Christoff, Ream, and Gabrieli (2001) contrasted the pattern of regional cerebral blood flow (rCBF) associated with rest with that seen during an arrow condition, in which subjects pressed a button box according to whether an arrow was pointing left or right. Rest minus arrow resulted in a pattern of activation remarkably similar to that seen in published autobiographical memory studies (e.g., activity in the anterotemporopolarcortex and the parahippocampal gyrus), such that a control condition of rest may fail to uncover specific regions involved in autobiographical recall (see also Conway et al., 2002). In addition, episodic tasks, such as paired-associate learning (Conway et al., 1999) and imagining events presented via sentences prior to scanning (Fink et al., 1996; Markowitsch et al., 2000), typically confound memory age: During the autobiographical task, subjects may produce old childhood memories, yet in the control condition they may be recalling very recent episodic events. In this paper, our interest was in neural regions that might be specific to different types of LTM, and, consequently, we chose a control condition involving the recall of semantic facts.

Notably, Maguire, Henson, et al. (2001), Maguire and Mummery (1999), and Maguire et al. (2000) adopted a $2 \times$ 2 factorial design that contrasted verification of timespecific (T) memories with those that were also personal (P) in nature (e.g., $\mathrm{T}+\mathrm{P}+=$ "You were Mike's best man at his wedding"; $\mathrm{T}+\mathrm{P}-=$ "Zola Budd tripped with Mary Decker"; $\mathrm{T}-\mathrm{P}+=$ "Ray is the youngest of your brothers"; and $\mathrm{T}-\mathrm{P}-=$ "Tony Blair has four children"). Maguire and Mummery reported a left lateralized network that supported all memory retrieval (all conditions minus a control sentence condition), including medial prefrontal cortex (BA 10), anterolateral middle temporal gyrus (BA 21), temporal pole (BA 38), hippocampus and parahippocampal gyrus (BA 28/38), posterior cingulate (BA 31), and, bilaterally, the temporoparietal junction (BA 39). In terms of memories that were specific in both time and place $(\mathrm{T}+\mathrm{P}+)$, there was particularly strong activation in left medial frontal regions: the hippocampus and the temporal pole. As we have already noted, however, despite the clever use of appropriate semantic control conditions, the autobiographical memory task in these studies was unlikely to result in retrieval of sensory-perceptual episodic memories (Conway et al., 2002), and it seems possible that the finding of a left-sided memory network in these studies is associated with this lack of specificity.

Laterality. As has been discussed above, the main controversy in the literature on autobiographical memory relates to the differential involvement of left versus right temporal lobe regions in retrieval. To address this controversy, it seems critical to compare blood flow in similar left and right regions directly, an analysis that has not yet been carried out in any published neuroimaging study on autobiographical memory. More specifically, if an activation passes a particular statistical threshold on the left but not on the right, it is not valid to conclude that the left activation is significantly greater than the right, since the signal could be very similar on the right but just marginally under the threshold. Similarly, even if there is statistically significant bilateral activation, there may still be large differences in the magnitude of activation between the two sides. In order to conclude that the signal change on one side differs from that on the other, the most appropriate test is to subtract the activations on each side from one another and test the difference statistically. Since this direct comparison has not been attempted in previous work in the field, current conclusions about the laterality of autobiographical activations can be viewed as only provisional.

\section{Summary}

Our experiment was aimed at addressing the methodological issues described above by adopting an innovative, neuropsychologicallyinformed experimental paradigm in which subjects are scanned while retrieving autobio- 
graphical or semantic information about concepts in response to the auditory presentation of the corresponding concept names. The technique we adopted is similar to methods considered well suited to probing the structure and content of human LTM in both normal subjects and patients: (1) retrieval of detailed and time-specific autobiographical memories related to a particular concept and from a particular time (Graham \& Hodges, 1997; Nestor et al., 2002) and (2) feature-listing experiments in which subjects are asked to speak (or write) at some length to describe what they know about everyday objects (e.g., Garrard, Lambon Ralph, Hodges, \& Patterson, 2001; Tyler, Moss, Durrant-Peatfield, \& Levy, 2000). In addition, the technique has the major advantage of allowing the subjects to provide the memories or factual material that they themselves consider relevant to the target concepts rather than forcing them to make judgments about experimenterdefined properties.

There were two other benefits associated with our experimental paradigm. First, it allowed us to record the responses of the subjects while they performed the experimental tasks, which, in turn, allowed us to undertake behavioral ratings of the memories and to confirm whether the subjects were performing our tasks appropriately. Second, the task provided a means of ensuring that the subjects would produce detailed and specific autobiographical events, thereby reducing the possibility that the task was dependent only on autobiographical knowledge.

In summary, our experiment (1) did not require pretesting of subjects prior to scanning, (2) allowed sufficient time for autobiographicalrecall, (3) included a suitable memory control condition (retrieval of semantic facts), (4) enabled us to collect and analyze the behavioral responses produced during the scanning event, and (5) provided an opportunity to carry out laterality analyses aimed at elucidating the roles of the right and left temporal lobe in autobiographical retrieval. Despite previous functional neuroimaging findings (at least in the autobiographical domain), we predicted, in accordance with data from neuropsychological studies, that there would be differential involvement of right- and left-sided regions in autobiographical and semantic retrieval, respectively.

\section{METHOD}

\section{Subjects}

A total of 24 healthy right-handed subjects (18 postmenopausal women and 6 men) with a mean age of 60.4 years $(S D=6.9$, range $=$ 42-68 years) were scanned. Each subject participated in one of three imaging studies. There were 7 subjects in Study 1 (mean age $=$ 63.6 years, $S D=4.4$, range $=57-68$ years), 8 subjects in Study 2 (mean age $=61.8$ years, $S D=6.2$, range $=51-68$ years), and 9 subjects in Study 3 (mean age $=56.7, S D=8.1$, range $=42-68$ years). The subjects were older than those commonly used in neuroimaging studies in order to ensure that autobiographical memories from the remote past (e.g., childhood and adulthood) would have occurred many years in the past. Prior to scanning, all the subjects were medically screened by a qualified clinician and gave written consent for participation in the study after its nature and possible consequences were explained to them. The study received ethical approval from the Cambridge Health Authority Local Research Ethics Committee.

\section{Image Acquisition}

Twelve PET scans were obtained for each subject using a GE Advance PET system (General Electric Medical Systems, Waukesha, Wisconsin) at the Wolfson Brain Imaging Centre, Addenbrooke's Hospital, Cambridge. Nine of the scans from Study 1 and 10 scans from each of Studies 2 and 3 are germane to the present paper. The GE system produces 35 simultaneous image slices per scan at an intrinsic resolution of approximately $4.0 \times 5.0 \times 4.5 \mathrm{~mm}$. Subjects received a 20 -sec intravenous bolus of $\mathrm{H}_{2}{ }^{15} \mathrm{O}$ before each scan through a forearm cannula at a concentration of $300 \mathrm{MBq} / \mathrm{ml}$ and a flow rate of $10 \mathrm{ml} / \mathrm{min}$. With this method, each scan provides an image of $\mathrm{rCBF}$ integrated over a period of $90 \mathrm{sec}$ from the time when the tracer first enters the cerebral circulation.

\section{Experimental Design}

Conditions and Stimuli. To select suitable stimuli for the experiment, we asked 3 control subjects (age range 55-65 years) to produce detailed autobiographical memories (both from the remote past and from the recent past) for 52 possible words (all highly imageable English nouns; e.g., horse, ambulance, fish, garden, bicycle, telephone) and recorded both the length of the interval between each subject's hearing the word and starting to speak and the length of time that the subjects took to describe their memories. On the basis of these responses, we selected words that (1) cued successful autobiographical recall in all subjects, (2) allowed the subjects to start speaking relatively quickly (within $5 \mathrm{sec}$ of hearing the word), (3) resulted in lengthy (at least 30-sec) and detailed (i.e., not general or repeated) autobiographical events, and (4) were equally successful in both the recent and remote domains. The final set of 36 words was randomly split into nine sets of 4 words, and the presentation of these sets (one per scan) was counterbalanced across conditions and subjects. Notably, very few of these words could be considered affect laden (i.e., likely to result in the retrieval of emotionally charged events), and, in keeping with this, the subjects rarely produced memories that were distressing or particularly emotive in nature.

In order to facilitate smooth autobiographical retrieval throughout the whole of the experimental scan, in all conditions the first word was presented to the subject $20 \mathrm{sec}$ prior to the start of the $90-\mathrm{sec}$ scanning period. This was followed by each of three words at 30 -sec intervals (see Figures 1A and 1B). Words were read aloud by the experimenter into an amplified sound system in the PET control room and delivered to the subject in the scanner via a pair of headphones. An auditory beep preceded the presentation of each word.

In Study 1, the subjects undertook six autobiographical memory $(\mathrm{ABM})$ scans, during which they were instructed to produce as detailed and time-specific an autobiographical memory as possible related to each presented concept. In three of the scans, this memory had to come from the last 5 years (recent), whereas in the three remaining ABM scans, a memory from childhood or early adulthood (remote) was requested. Comparisons of the patterns of activations during these two conditions (recent-remote and remote-recent) revealed no regions significant at a corrected level, so data from these conditions were combined in subsequent analyses. During three other scans, the subjects were requested to produce semantic (SEM) facts about the heard word, including both perceptual and nonperceptual information, as they wished (see Figure 1B and Table 1). If during any of the conditions the subject was unable to produce information about a word, the experimenter provided the subject with a new word from a prepared list of alternates on the basis of the pilot testing.

In Study 2, the stimuli for all conditions were highly imageable English nouns balanced across semantic domains-and the autobiographical condition - for familiarity and syllable length. Since the 
(A) Produce a detailed recent (REC) or remote (REM) autobiographical event related to the word (ABM, Study 1 )

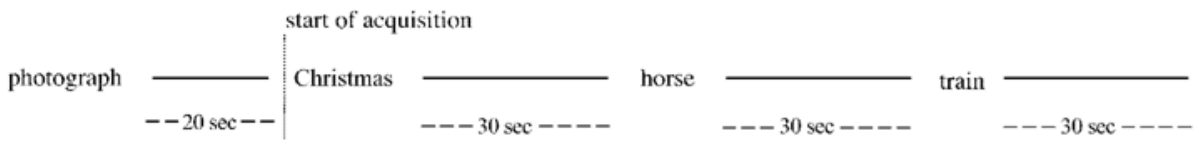

(B) Produce semantic facts about the word (SEM, Study 1)

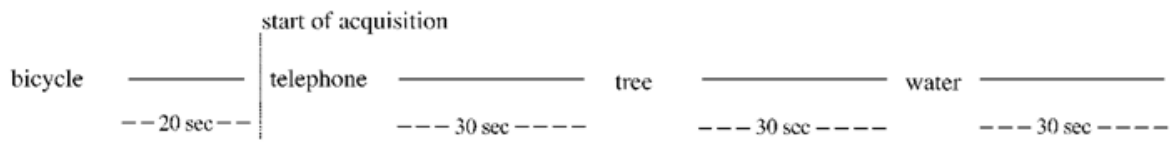

(C) Produce perceptual (P) or nonperceptual (NP) information related to the word (SEM, Study 2)

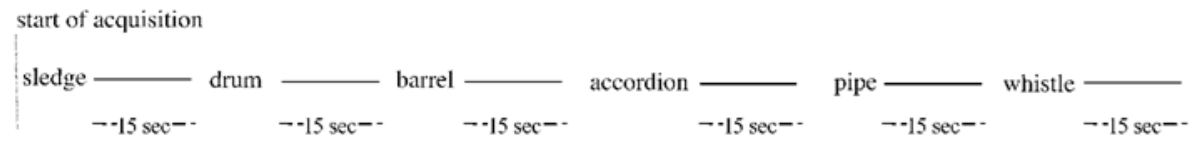

(D) Produce a detailed remote (childhood/early adulthood) autobiographical event related to the word (ABM, Study 2)

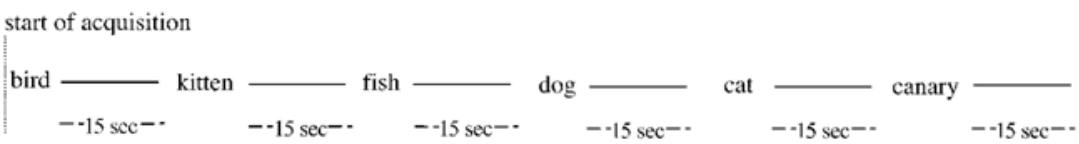

(E) Produce a detailed autobiographical event related to the word from any time period (ABM, Study 3 )

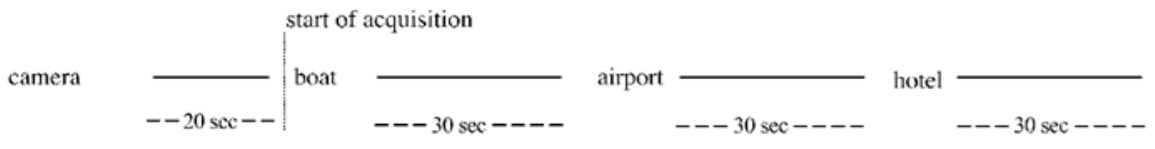

(F) Produce semantic facts related to the word (SEM, Study 3)

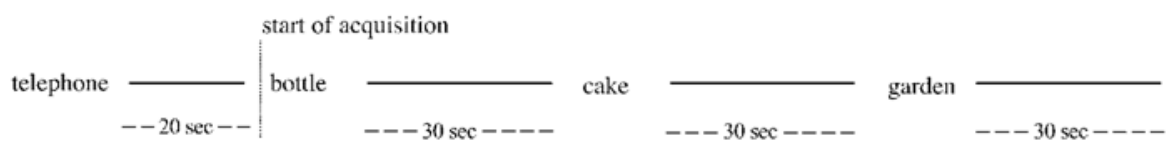

(G) Produce semantic facts about a famous person related to the word (FP, Study 3)

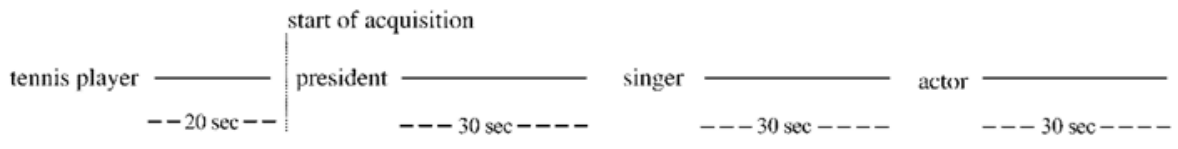

(H) Produce semantic facts about a personal person related to the word (PP, Study 3)

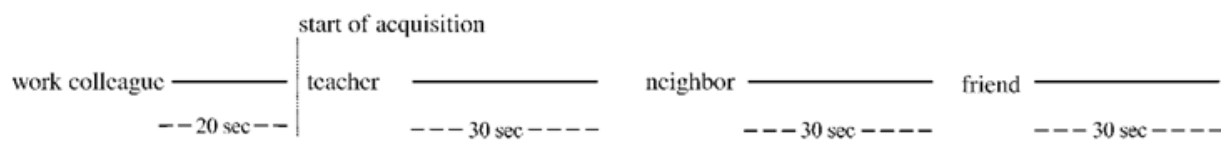

(I) Produce semantic facts about a famous event related to the word (FEV, Study 3)

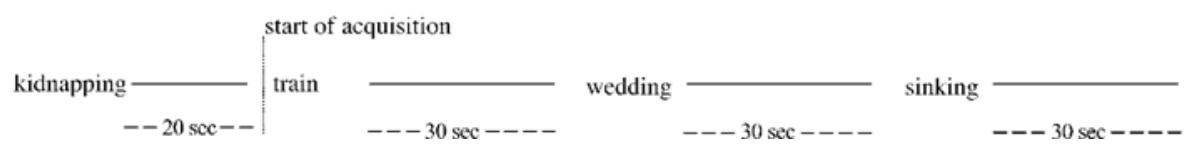

Figure 1. Examples of the experimental design and stimuli used in the three imaging studies and across conditions. 
Table 1

Examples of Subjects' Responses in Studies 1, 2, and 3

\begin{tabular}{|c|c|}
\hline Study: Condition & Word and Sample Response \\
\hline 1: Recent ABM & $\begin{array}{l}\text { Squirrel: I'd taken the dog for a walk in the park and I didn't think he had seen } \\
\text { a squirrel before, so I thought this should be quite interesting because he's not } \\
\text { interested in cats. He, the squirrel, stayed absolutely still on the side and my } \\
\text { dog walked up to it and they were within, oh, just a few inches of each other } \\
\text { before the squirrel just gently took off. }\end{array}$ \\
\hline 1: Remote ABM & $\begin{array}{l}\text { Wedding: When I was about four, my Auntie Anne married my Uncle Tom } \\
\text { and right from a very small child I didn't very much like getting dressed up, } \\
\text { but I had to be dressed in a little beautiful pink frock and I had a wicker basket } \\
\text { with flowers in it. }\end{array}$ \\
\hline 1: SEM & $\begin{array}{l}\text { Airplane: An airplane is an invention of this century and it transports people } \\
\text { through the sky to many countries, more or less anywhere in the world, and } \\
\text { aircraft vary in size, you can have small ones with just one pilot and you can } \\
\text { have ones with hundreds of people in that. }\end{array}$ \\
\hline 2: ABM & $\begin{array}{l}\text { Dog: I wasn't a dog person a long while ago. But when I was a very small boy, } \\
\text { I patted a little dog on the head and it snapped at me, and I've still got a scar. }\end{array}$ \\
\hline 2: L-P & $\begin{array}{l}\text { Alligator: An alligator is fairly long, I should say an eight, nine, ten feet long } \\
\text { creature which lives, it splashes about in the water. It's green, dirty greenish } \\
\text { sort of olive color. }\end{array}$ \\
\hline 2: L-NP & $\begin{array}{l}\text { Eagle: It's an endangered species, protected, you can't collect their eggs. } \\
\text { It lives in mountains in Scotland. }\end{array}$ \\
\hline 2: NL-P & $\begin{array}{l}\text { Barrel: Is a roundish object made of wood, held together with metal hoops and } \\
\text { a lid on the top and on the bottom. It contains things like beer or wine and it } \\
\text { would be very rough on the outside. }\end{array}$ \\
\hline 2: NL-NP & $\begin{array}{l}\text { Trumpet: A trumpet is a musical instrument. It's made of brass, it's played in an } \\
\text { orchestra usually in large numbers. It can be played solo or in small groups. }\end{array}$ \\
\hline 3: ABM & $\begin{array}{l}\text { Bicycle: My daughter borrowed my bicycle to go on holiday to Ireland. She } \\
\text { went with her boyfriend and we had this postcard back and she said we're still } \\
\text { speaking, he's waiting to catch up, but the bike is a super one. }\end{array}$ \\
\hline 3: SEM & $\begin{array}{l}\text { Ambulance: Ambulances are used for accidents in emergencies, quickly to get } \\
\text { to places. Very well equipped to deal with all types of accidents and } \\
\text { emergencies. Also smaller ambulances used for transporting patients from } \\
\text { their homes to their hospitals or between one hospital and another. }\end{array}$ \\
\hline 3: FEV & $\begin{array}{l}\text { Bombing: The one at Enniskillen on Memorial Sunday. I have a friend from } \\
\text { there and she knew lots of people who had been at the cemetery, at this } \\
\text { service and people who were actually hurt in the blast. }\end{array}$ \\
\hline 3: FP & $\begin{array}{l}\text { Politician: I should think we could go for Margaret Thatcher. Margaret, the Iron } \\
\text { Lady, who turned round this country in many ways and made I think this } \\
\text { country into a much more international force. She was well respected } \\
\text { by European leaders. }\end{array}$ \\
\hline 3: PP & $\begin{array}{l}\text { Teacher: The most charismatic teacher that I had was Jim Simpson who was my } \\
\text { biology teacher and he had an ability to draw on the board which was quite } \\
\text { remarkable. He was a large man. }\end{array}$ \\
\hline
\end{tabular}

Note-ABM, autobiographical memory; SEM, semantic memory; L, living; P, perceptual; NL, nonliving; NP, nonperceptual; FEV, famous events; FP, famous people; PP, personal people.

experiment was designed primarily to ask whether semantic memory is organized by attribute, by category, or by both (see Lee et al., 2002), there were four SEM conditions (living-perceptual, livingnonperceptual, nonliving-perceptual, and nonliving-nonperceptual ). During the living tasks, the subjects were presented with names of animals (e.g., lobster, tiger, fox); during the nonliving conditions, the subjects were presented with names of artifacts (e.g., hammer, whistle, windmill; see Figure 1C). The subjects were instructed to produce semantic information about each object by speaking aloud following its presentation. The content of the requested information was varied according to the task (see Table 1 for examples). Thus, during the perceptual tasks, the subjects were instructed to generate information of a perceptual nature (e.g., "a fox is often red in color with a bushy tail..."), whereas during the nonperceptual tasks, the subjects were asked to produce information of a nonperceptual nature (e.g., "foxes are hunted by hounds and are considered pests in cities..."). The experimental task lasted $90 \mathrm{sec}$ and comprised six stimuli presented for $15 \mathrm{sec}$ each (see Figures 1C and 1D); unlike in Study 1, there were no additional items presented prior to the start of acquisition. The stimuli were completely counterbalanced across subjects such that words assigned to the nonperceptual tasks for half of the subjects were used in the perceptual tasks for the other half.

For the purposes of this experiment, we have combined all these scans into a single SEM condition (details about the differences between the semantic conditions are reported in Lee et al., 2002). This was considered appropriate, since the subjects in Studies 1 and 3 were free to produce both perceptual and nonperceptual information and were provided with concepts of both living and nonliving things. The stimuli for the ABM condition in Study 2 were similar to the items used in Study 1, but were also selected so as to be matched, for familiarity and category, to the SEM conditions (e.g., one scan included only living items and the other comprised only nonliving 
items). The subjects were asked to produce memories from childhood and early adulthood, except that in Study 2 the subjects were provided with only $15 \mathrm{sec}$ during which to discuss the event (see Figure 1D). A reduced time period was adopted in this experiment because pilot testing of the semantic definition component revealed that subjects might not be able to produce exclusively perceptual or nonperceptual information for $30 \mathrm{sec}$.

Ten scans from Study 3 are relevant to our investigation. Two of these were $\mathrm{ABM}$ in nature, during which the subjects were requested to produce a detailed and time-specific memory from any time period they wished (note that this is somewhat different from the methods used in other studies, in which the time period for retrieval was clearly specified; see Figure 1E). As in Study 1, there were also two SEM scans, during which the subjects produced a series of semantic facts about the presented words (see Figure 1F). The additional three conditions (2 scans each) were as follows: famous people (FP; see Figure 1G), personal people (PP; see Figure 1H), and famous events (FEV; see Figure 1I). In order to equate these three new conditions to the ABM and SEM conditions, we used labels rather than names of specific people or events (e.g., for FP, actor, tennis player, entrepreneur; for PP, neighbor, driver, grandchild; for FEV, bombing, train, sinking). Examples of the subjects' responses are shown in Table 1. In Study 3, we were able to return to longer time periods for the responses to target stimuli and, as in Study 1, the subjects heard four words per scan, with the first word being presented $20 \mathrm{sec}$ prior to the start of the 90 -sec activation scan. The words for the $\mathrm{ABM}$ and SEM conditions were based on items used in the two previous studies. The stimuli for the new conditions were obtained by pilot testing 3 appropriately aged control subjects and selecting items for which (1) there was successful autobiographical recall in all 3 subjects, (2) the subjects started speaking within $5 \mathrm{sec}$ of hearing the word, and (3) the descriptions of the people and events were detailed and lasted at least $30 \mathrm{sec}$. The subjects were given detailed instructions and adequate practice with all these tasks before entering the scanner and, prior to each scan, were reminded of these instructions with particular reference to the condition in which they were about to participate.

Behavioral analyses. During the scans, the subjects' responses were tape recorded and later transcribed. Two raters blind to the hypotheses of the experiment then rated all the ABM and SEM responses. In all analyses, only those items presented in the first 45-60 sec of scanning, during the rise time of the head curve (Silbersweig et al., 1993), were included (e.g., in Studies 1 and 3 items in Positions 2 and 3 , and in Study 2 the first three words). The raters were trained to score the responses and were provided with clear and detailed scoring systems to help them judge the quality of the descriptions.

For the ABM condition, responses were rated according to specificity (semantic, generic, and specific) and detail (on a scale of 0-5), using a novel modification of a 6-point scoring scheme developed for use in neuropsychological patients (Graham \& Hodges, 1997). To create a single measure for the episodic quality of each response and to generate as sensitive a rating scale as possible, a semantic memory was given 0 points, a generic memory (e.g., "I eat toast for breakfast every day") 5 points, and a specific memory (e.g., "My toaster caught fire one morning") 10 points. Points for detail $(0-5)$ were added to these scores, and, therefore, the maximum possible score for a memory was 15 points.

Responses in the SEM condition were rated for degree of perceptual and nonperceptual/ factual information (rated on a scale of $0-4$, with 0 indicating information that was entirely nonperceptual and 4 indicating information that was entirely perceptual). In all analyses, each response was entered as a separate score, even though there might be two or three individual responses within a scan.

\section{Data Preprocessing and Statistical Analysis}

The scans were preprocessed individually and then combined with the other subjects' scans for collective statistical analysis using the Statistical Parametric Mapping 99 package (SPM99, Wellcome Department of Imaging Neuroscience, London). For preprocessing, the functional images were first realigned as implemented in SPM99 to create a mean image. This was then normalized for global CBF value and also spatially normalized to conform to the standard Montreal Neurological Institute (MNI) brain template. Finally, each image was spatially smoothed using an isotropic Gaussian kernel at $16 \mathrm{~mm}$.

For the statistical analysis, the global CBF value was averaged across subjects for each activation state. Blood flow changes between conditions were then estimated for each voxel according to the general linear model, as implemented in SPM99. Scan order and head movement were entered as covariates of noninterest in the analysis (Brett, Bloomfield, Brooks, Stein, \& Grasby, 1999). Activations within the temporal lobes that survived an intensity threshold of $p \leq .05$ (corrected for multiple comparisons) are reported. This threshold, based on 3-D Gaussian random field theory, predicts the likelihood of obtaining a false positive in an extended 3-D field. To estimate the Brodmann areas (BAs) corresponding to regions of significant activation, the MNI coordinates provided by SPM99 were transformed (see http://www.mrc-cbu.cam.ac.uk/imaging/ mnispace.html) to Talairach atlas coordinates (Talairach \& Tournoux, 1988). Three separate analyses, each addressing specific experimental questions, were carried out and are described below.

\section{RESULTS}

\section{Analysis 1: Is the Retrieval of Autobiographical Memory Dependent on a Predominantly Left Hemispheric Network?}

In the first analysis, data from the ABM and SEM conditions in all 24 subjects participating in Studies 1-3 were combined, and two contrasts were carried out: (1) ABM SEM, to identify the brain regions involved in autobiographical recall in comparison with the retrieval of general semantic information, and (2) SEM - ABM, to determine which areas showed significant $\mathrm{CBF}$ increase during the recall of general semantic knowledge in comparison with that of personal events.

Behavioral performance. Across all subjects, a total of 136 autobiographicalmemories were included in the analysis. The average episodic specificity for these memories was $7 / 15(S D=2.2)$. Descriptive statistics for the semantic memories, of which 235 were included in the analysis, revealed that across all the studies the memories contained similar amounts of nonperceptual and perceptual information (average score $=1.9, S D=1.5$ ). This would not necessarily be true of all memories, since one of the aims of Study 2 was to directly contrast the brain regions involved in the retrieval of perceptual versus nonperceptual semantic knowledge (Lee et al., 2002).

Blood flow changes. Subtracting the SEM condition from the ABM condition (ABM - SEM) yielded significant $\mathrm{rCBF}$ increase in a number of regions (see Figure 2A), including bilateral activations in medial frontal $[\mathrm{BA} 9 / 10, p$ (corr) $=.001]$ and middle temporal [BA 21, $p($ corr $)=.01]$ regions. There were also significant activations in the left posterior cingulate gyrus $[p$ (corr) $=$ $.001]$, left anterior cingulate cortex $[p($ corr $)=.01]$, and left inferior temporoparietal cortex [BA 39, $p$ (corr) $=$ $.01]$. Activity in a region in the right inferior parietal lobe 


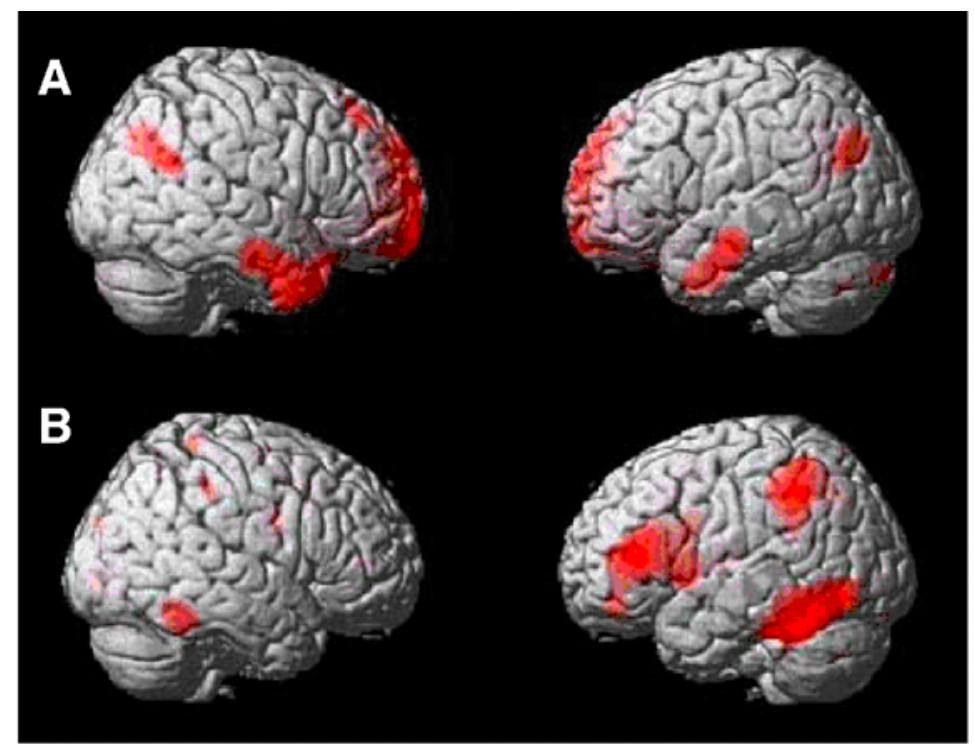

Figure 2. Regions of significant regional cerebral blood flow change when (A) the semantic condition was subtracted from the autobiographical condition (ABM - SEM) and (B) the autobiographical condition was subtracted from the semantic condition (SEM - ABM), superimposed on an average 3-Drendered MRI scan.

[BA 39/40, $p($ corr $)=.08]$ approached significance (see Table 2).

The opposite contrast (SEM-ABM) revealed a left lateralized network of frontal and temporal regions (see Fig- ure 2B): ventrolateral prefrontal cortex [BA 45, $p$ (corr) $=$ $.001]$, posterior inferior temporal gyrus [BA 37, $p$ (corr) $=$ $.001]$, and inferior parietal lobe [BA 40, $p$ (corr) $=.001$ ]. Activity in no other regions was significant at a corrected

Table 2

Stereotaxic Coordinates of Significant rCBF Change When Autobiographical Memory and Semantic Memory Were Contrasted

\begin{tabular}{|c|c|c|c|c|c|}
\hline \multirow[b]{2}{*}{ Region } & \multicolumn{4}{|c|}{$\underline{\text { Stereotaxic Coordinates }}$} & \multirow[b]{2}{*}{$z$ score } \\
\hline & BA & $x$ & $y$ & $z$ & \\
\hline \multicolumn{6}{|c|}{ Autobiographical - Semantic } \\
\hline \multicolumn{6}{|l|}{ Left hemisphere } \\
\hline Medial frontal cortex & 10 & -4 & 54 & -9 & $6.1 *$ \\
\hline Middle temporal cortex & 21 & -59 & -12 & -15 & $6.1 *$ \\
\hline Posterior cingulate cortex & 31 & -6 & -55 & 32 & $5.8^{*}$ \\
\hline Anterior cingulate cortex & 32 & 0 & 30 & -13 & $5.2 *$ \\
\hline Inferior temporoparietal cortex & 39 & -51 & -66 & 31 & $4.6^{*}$ \\
\hline \multicolumn{6}{|l|}{ Right hemisphere } \\
\hline Medial frontal cortex & 9 & 4 & 57 & 17 & $6.9^{*}$ \\
\hline Middle temporal cortex & 21 & 50 & 4 & -36 & $5.8^{*}$ \\
\hline Middle temporal cortex & 21 & 63 & -11 & -18 & $5.2^{*}$ \\
\hline Inferior parietal cortex & $39 / 40$ & 55 & -55 & 29 & 4.4 \\
\hline Superior frontal cortex & 8 & 26 & 39 & 42 & 4.1 \\
\hline \multicolumn{6}{|c|}{ Semantic - Autobiographical } \\
\hline \multicolumn{6}{|l|}{ Left hemisphere } \\
\hline Ventrolateral frontal cortex & 45 & -44 & 31 & 8 & $7.3^{*}$ \\
\hline Inferior parietal cortex & 40 & -50 & -43 & 37 & $6.4^{*}$ \\
\hline Posterior inferior temporal cortex & 37 & -51 & -49 & -14 & $6.6^{*}$ \\
\hline Inferior frontal cortex & 44 & -50 & 9 & 24 & 3.9 \\
\hline Superior temporal cortex & 22 & -48 & 8 & 1 & 4.3 \\
\hline \multicolumn{6}{|l|}{ Right hemisphere } \\
\hline Posterior inferior temporal cortex & 37 & 61 & -47 & -14 & 4.1 \\
\hline Dorsolateral frontal cortex & 46 & 50 & 43 & 5 & 3.2 \\
\hline
\end{tabular}

*Survives $p=.05$ corrected for multiple comparisons. 
level, although activity in the right posterior inferior temporal gyrus (BA 37) and that in the dorsolateral frontal cortex (BA 46) were significant at an uncorrected level (see Table 2).

Comment. Our first analysis, which included all available ABM and SEM scans across the three studies, suggests that the right and left temporal (and frontal) lobes play differential roles in human LTM. Whereas autobiographical memory, in comparison with a well-matched semantic retrieval condition, resulted in increased $\mathrm{rCBF}$ in bilateral anterior temporal and medial frontal regions, the semantic condition activated a network that appeared to be left lateralized, including more posterior temporal regions (BA 37) and dorsolateral prefrontal cortex (BA 46). This finding indicates that the retrieval of autobiographical memories does not depend solely on a left-lateralized network of brain regions (Conway et al., 1999; Maguire, 2001; Maguire \& Mummery, 1999) and is consistent with studies of neuropsychological patients, in which a severe autobiographical memory deficit more typically arises from right-sided or bilateral temporal/frontal lobe damage (Conway \& Fthenaki, 2000; Eslinger, 1998; Graham \& Hodges, 1997; Kopelman \& Kapur, 2001; Kroll et al., 1997; Nestor et al., 2002).

It has previously been proposed that right hemispheric activations in autobiographical memory (Fink et al., 1996; Markowitsch et al., 2000) may be a consequence of the retrieval of emotional memories (Conway \& Fthenaki, 2000; Fink et al., 1996; Maguire, 2001). This seems an unlikely explanation for our activation patterns, given that our cue words were rarely emotional and that most of the autobio- graphical memories produced by the subjects were nonemotion-laden personal events (e.g., seeing a squirrel while walking a dog, borrowing a bicycle to go on vacation; see Table 1). We suggest, instead, that the finding of right temporal and frontal activationsin our autobiographical task reflects the use of a paradigm in which the subjects were provided with sufficient time to retrieve detailed memories (or sensory-perceptual episodic memories; Conway, 2001). By contrast, the methods adopted by other researchers may have taxed less specific levels of autobiographical knowledge (e.g., lifetime periods and/or general events) that are more dependent on left temporal structures (Conway et al., 1999; Maguire \& Mummery, 1999).

\section{Analysis 2: Influence \\ of Autobiographical Specificity}

In the second analysis, we tested our hypothesis that the mainly left-sided activations in previous neuroimaging studies of autobiographicalmemory occurred because the subjects had been asked to produce and/or verify autobiographical knowledge as opposed to retrieving detailed and specific autobiographical memories. Owing to the nature of the material to be produced in Study 2, the subjects were provided with $15 \mathrm{sec}$ as opposed to $30 \mathrm{sec}$ per item. This methodological change allowed us to investigate the influence of retrieval time and, by inference, autobiographical specificity on patterns of activation during the production of autobiographical memories. Assuming some validity for our explanation of the strong right temporal lobe activation reported in Analysis 1, we expected

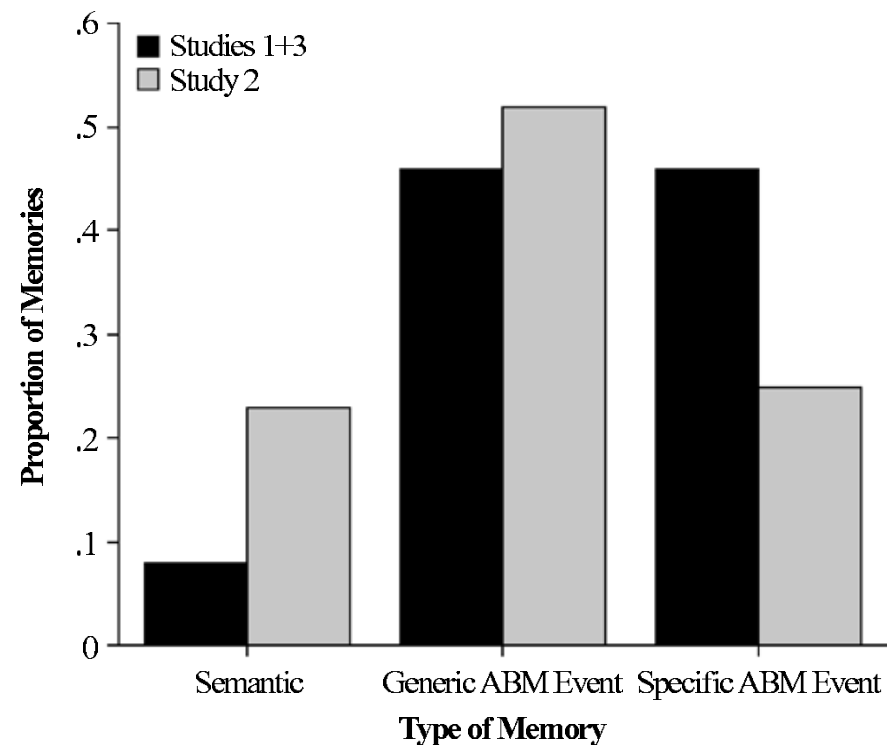

Figure 3. Proportion of memories from Studies 1 and $3(n=112)$ in comparison with those from Study $2(n=57)$ classified as semantic (0-4.9), a generic autobiographical episode (5-9.9), or a specific autobiographical episode (10-15) on the basis of the mean average rated score (out of 15). 
more right-sided temporal lobe involvement in Studies 1 and 3 than in Study 2. To test this prediction, prior to carrying out a laterality analysis, we first investigated which areas were activated in the three separate studies.

Behavioral performance. To determine whether the autobiographical memories produced by the subjects in Studies 1 and 3 were more specific than those recalled by those in Study 2 (presumably due to the shorter time window available in Study 2), we reanalyzed our behavioral data with study as an independent factor. This analysis confirmed a significant effect of study on the quality of the autobiographical memories produced by the subjects $[F(1,167)=11.7, p<.001]$. The average specificity score for Studies 1 and 3 was higher $(9.1, S D=2.6)$ than that in Study $2(7.7, S D=2.5)$. A second analysis of the behavioral data revealed that the difference between Studies 1 and 3 and Study 2, albeit small, mapped onto a real qualitative distinction in terms of autobiographical speci- ficity. The memories produced by the subjects were categorized into the three basic types of (1) semantic, (2) a generic autobiographical event, and (3) a specific autobiographical event, depending on the average score obtained from the two raters (e.g., $0-4.9=$ semantic, 5$9.9=$ generic , and $10-15=$ specific). As is shown in Figure 3 , almost all the memories produced by the subjects in Studies 1 and 3 were of either specific (46\%) or generic $(46 \%)$ autobiographical events. Very few memories were classified as semantic (8\%). By contrast, in Study 2, only $25 \%$ of the memories were of specific autobiographical episodes (i.e., events judged unique in time and place). Fifty-two percent were generic memories, with the remaining $23 \%$ being classified as semantic. In summary, whereas similar numbers of generic memories were produced in all the studies, in Studies 1 and 3 there was a strong bias toward more specific autobiographical events, whereas in Study 2 the subjects were more likely to produce seman-

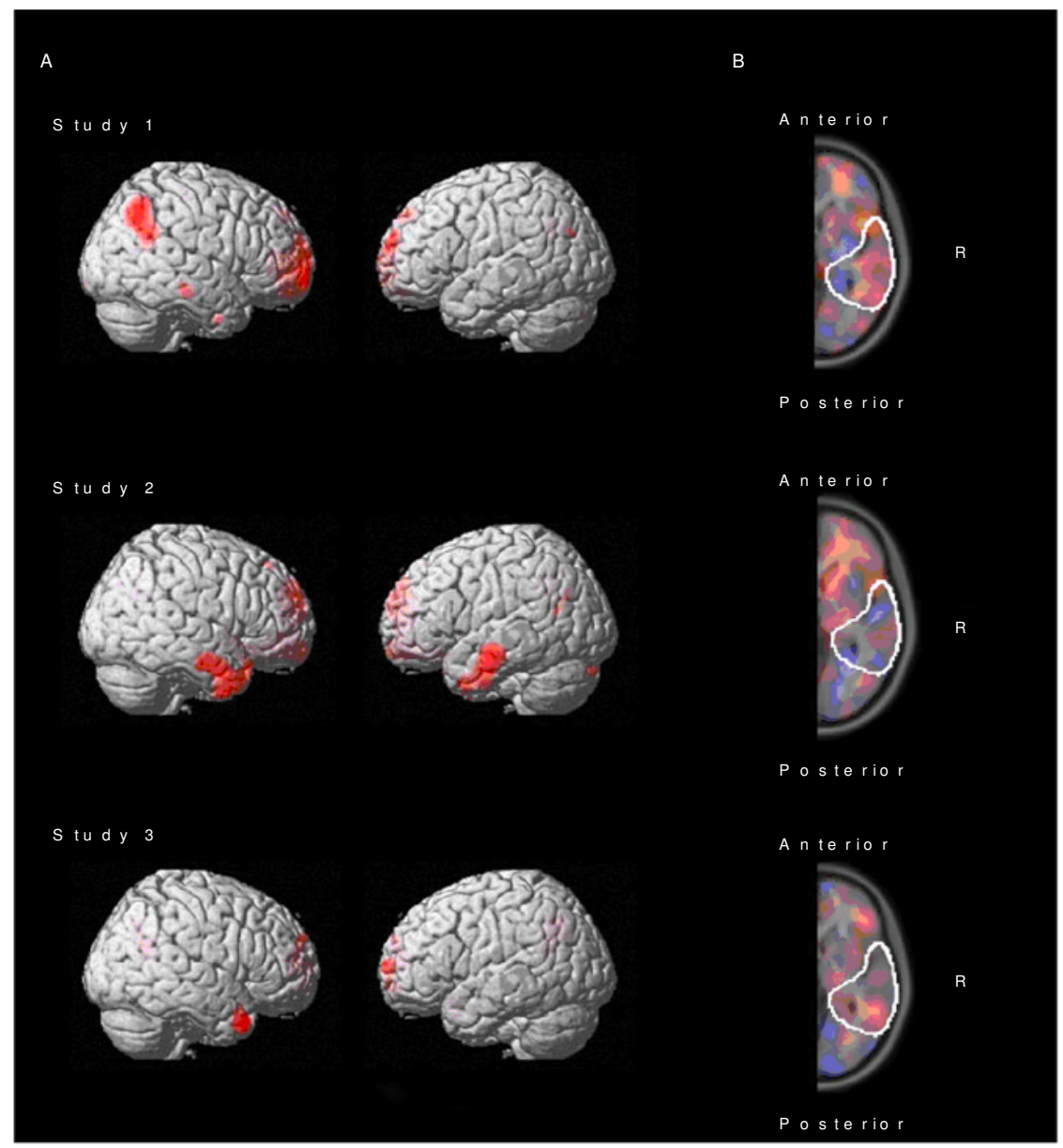

Figure 4. Diagram showing (A) the regions of significant regional cerebral blood flow change and (B) the laterality map for the autobiographical minus semantic (ABM - SEM) contrast for the three studies. For the laterality maps (see text for details about how these were created), a single right hemisphere transverse slice is shown $(z=0)$. The red shading indicates greater activation in the right hemisphere, and the blue shading, greater activation in the left hemisphere. The temporal lobe is outlined in white. 


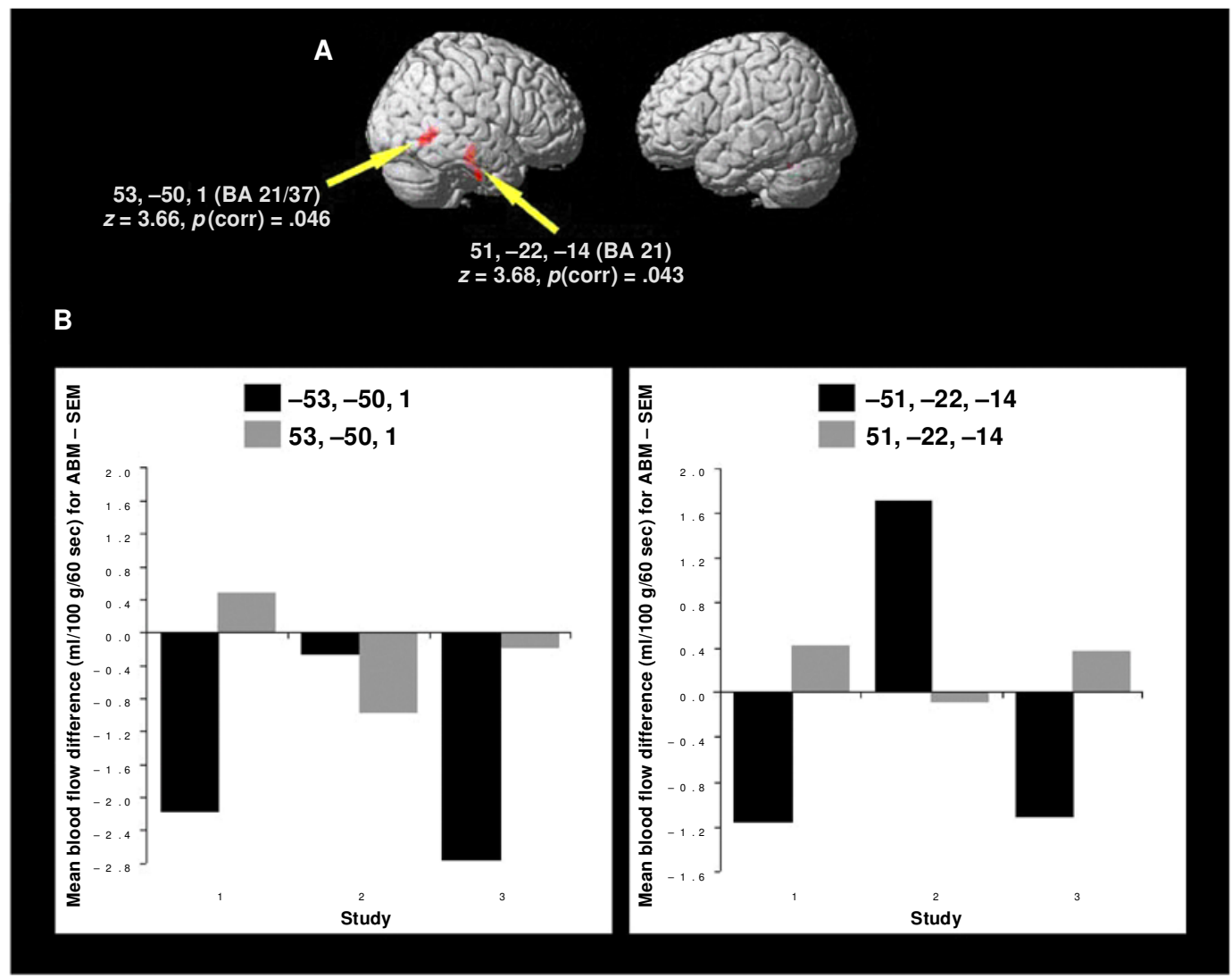

Figure 5. Diagram showing (A) the regions that were significantly different between the average laterality map from Studies 1 and 3 in comparison with the map from Study 2 for the autobiographical minus semantic (ABM SEM) contrast and (B) the mean difference in blood flow between the ABM and SEM conditions for the two significantly activated foci (left and right).

tic information about the cue word. A $\chi^{2}$ analysis confirmed that these numerical differences were significant $\left(\chi^{2}=11 / 35, p<.005\right)$.

An analysis of the semantic memories revealed that the amount of nonperceptual versus perceptual information produced by the subjects was also different across studies $[F(1,233)=4.8, p<.05]:$ The subjects in Studies 1 and 3 produced more nonperceptual information $(1.6, S D=$ .79) than did those in Study $2(2.1, S D=1.7)$.

Blood flow changes. Figure 4A illustrates the regions of significant $\mathrm{rCBF}$ change for each study in the ABM SEM contrast. Whereas in all three studies there was clear involvement of right anterior temporal regions, significant changes in the left temporal lobe (at a corrected level) were seen only in Study 2. This pattern implies that there may be greater activation on the left than on the right in Study 2 in comparison with Studies 1 and 3. As was noted in the introduction, a direct test of this hypothesis is to subtract the activation in the left hemisphere from the activation in the right hemisphere and determine whether any differences are statistically significant.

Laterality maps were produced by flipping the contrast image for the ABM - SEM comparison from each study about the interhemispheric fissure and subtracting this flipped image from the original contrast image. After this subtraction, the right half of the image will be positive for regions that have increased blood flow in the right hemisphere and negative for regions that have increased blood flow in the left hemisphere. This manipulation allows us to test whether there was any left or right bias in temporal lobe activation(s) during autobiographical retrieval. These maps are shown in Figure 4B, where the red shading indicates regions that had greater $\mathrm{rCBF}$ in the right than in the left hemisphere and the blue shading indicates regions with greater blood flow in the left than in the right hemisphere. In the temporal lobes (outlined in white), there was a greater right-sided emphasis (red shading) in Studies 1 and 3 than in Study 2.

For an assessment of statistical differences between the laterality maps shown in Figure 4B, the ABM - SEM laterality images for each individual subject were entered into an SPM99 analysis of variance (ANOVA) with the three studies as a factor, allowing us to subtract Study 2 from Studies 1 and 3. Small volume correction was used to restrict the analysis to the temporal lobe. Two regions showed evidence of a laterality difference: Activity in the 
right middle temporal gyrus (BA 21) and the right posterior temporal cortex (BA 21/37) was significant at a small volume corrected level ( $p<.05$; see Figure 5A). Figure $5 \mathrm{~B}$, in which the mean difference in blood flow between the autobiographical and semantic conditions for the two foci (left and right) in each of the three studies is plotted, confirms this pattern. In Studies 1 and 3, there was activation in these regions in the right hemisphere with deactivation in the left, whereas the opposite pattern-activation in similar areas in the left hemispherewas seen in Study 2 for the middle temporal gyrus.

Comment. Our second analysis was designed to detect different patterns of activation between Study 2 (in which there was a reduced period of time $-15 \mathrm{sec}$ - available for subjects to retrieve and describe the requested information) and Studies 1 and 3 (in which $30 \mathrm{sec}$ per item were provided). Two distinct but related patterns were evident. First, there was increased activation in the left temporal lobe in Study 2 in comparison with that in Studies 1 and 3. This finding initially seems puzzling: The subjects in our studies performed the identical task (i.e., retrieval of a memory from a cue word), and, although we predicted involvement of the left temporal lobe in this test (as has been documented by other researchers), we did not expect differential profiles of left activation for the ABM - SEM contrast across studies. A possible explanation for this pattern is evident from our behavioral analyses of the semantic conditions. The subjects in Studies 1 and 3 were more likely to produce nonperceptualinformation during recall, whereas the subjects in Study 2 produced equivalent amounts of both nonperceptual and perceptual knowledge. In Lee et al. (2002), which was based on a more detailed analysis of the data from our Study 2, the retrieval of nonperceptual information activated an area in left middle temporal cortex close to that revealed in Study 2 for auto- biographical retrieval, whereas recall of perceptual knowledge about concepts resulted in greater activation of left posterior inferior temporal cortex (BA 37). It seems plausible, therefore, that the significantly greater involvement of left middle temporal gyrus in our Study 2 in comparison with that found in Studies 1 and 3 may reflect the fact that the semantic conditions included in Studies 1 and 3 were skewed toward recall of nonperceptual information and, therefore, the ABM - SEM contrast was less likely to reveal significant engagement of left middle temporal regions.

The second finding of interest was as predicted: Two right temporal lobe regions showed significantly greater activation in Studies 1 and 3 (especially in Study 1) in comparison with Study 2. Considered alongside the behavioral data, in which raters scored the memories from Study 2 as less detailed and less autobiographically specific than those produced by the individuals in Studies 1 and 3, these findings imply that the amount of right temporal lobe involvement evident in a neuroimaging study of autobiographical memory may reflect the demands placed on the individual in terms of autobiographical reconstruction.

More specifically, to return to Conway's (2001) description of the processes involved in the autobiographicalcueword technique, the subjects in Conway et al. (1999) may have got only as far as thinking about "when I was at university" or about a more refined cue, such as "working at orientation week," but not to any actual episodes or events. In Maguire and Mummery (1999) and Maguire et al. (2000), lifetime period knowledge, such as "that was when we lived in city $\mathrm{X}$ in the house at Y," was presumably sufficient to solve the task. In our studies, however, we conclude that the subjects accessed recollective episodic memories (e.g., "saw it in a sale at store W") and eventspecific details associated with the event, albeit to a greater extent in Studies 1 and 3 than in Study 2.
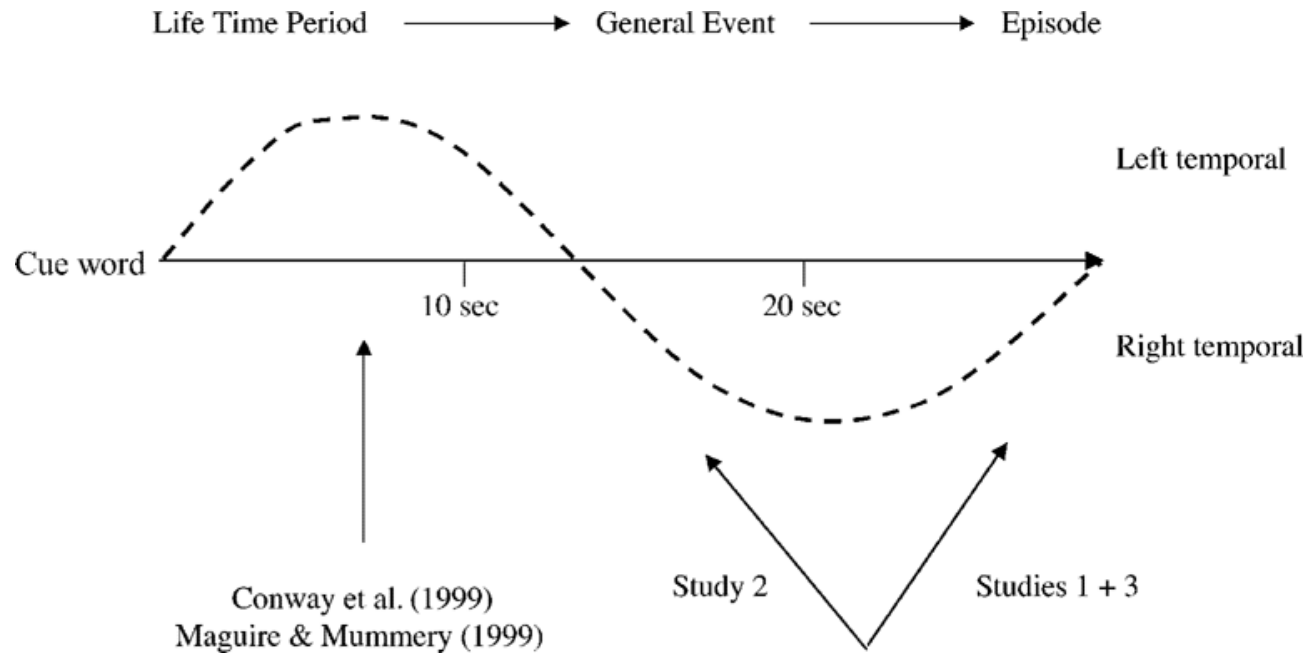

Figure 6. Schematic diagram showing how retrieval of an autobiographical memory associated with a cue word may initially recruit left temporal structures, but later may be more dependent on the right temporal lobe. 
Our interpretation is shown schematically in Figure 6. Anatomically, there is an initial dependence on left temporal lobe regions, in processing the meaning of the cue word and moving systematically through lifetime periods and general events, prior to more involvement of right temporal lobe structures during the production of the recollective experience. Most of the published studies fall close to the left side of the schematic and, consequently, report significant involvement of left temporal regions (Conway et al., 1999; Maguire \& Mummery, 1999). Our studies fall more to the right of the schematic and reveal evidence of bilateral temporal lobe involvement over the course of the scan (see also Fink et al., 1996; Markowitsch et al., 2000), with a stronger dependence on the left in Study 2.

The findings of Ryan et al. (2001) are not entirely consistent with this hypothesis. They found no evidence of right temporal lobe activation during their autobiographical memory condition (4 out of 7 subjects showed significant activation in an area in the left middle temporal gyrus [BA 21, $\{-60,-8,-4\}]$ close to that activated in our Analysis 1 [BA 21, $\{-59,-12,-15\}])$, despite the use of a similar cue-word paradigm and the provision of $20 \mathrm{sec}$ for recall. Ryan et al.'s analysis, however, was based on a comparison of the regions that were significantly active during recall of recent and remote memories and during rest and sentence completion. As was mentioned in the introduction, in Christoff et al. (2001) a rest condition produced patterns of activation similar to those seen in autobiographical memory studies (bilateral temporopolar activation and medial frontal cortex), and it is thus possible that the lack of right temporal region involvement in Ryan et al.'s study could be attributable to the control tasks, especially if rest activates right anterior temporal regions in particular.

Having established clear involvement of both right and left anterior temporal lobe structures in autobiographical memory retrieval in our study, at least when this type of memory is contrasted with the recall of general semantic facts, we now turn to a more cognitively challenging question: What is the nature of the autobiographical "representations" in the temporal lobes? More specifically, do the findings reported here indicate that these brain regions are the repository for autobiographical events from the past and, furthermore, that there is real neural separability between a bilateral and anteriorly located autobiographical database and a more unilateral and left posterior representation of semantic knowledge about objects, concepts, and the meanings of words?

Although the ABM task used here was designed to be very similar to that of the general semantic test (e.g., both required a search for and selection of appropriate responses and the production of a sequence of subevents or subfacts), there are, nonetheless, some significant differences in the two conditions, which may have resulted in the distinct profiles revealed in our study. As was mentioned previously, although autobiographical memory is often more emotionally demanding than retrieval of a series of semantic facts about a concept, we are confident from the stimulus selection and subject responses that this difference was not the cause of the observed differences. A more likely candidate, we believe, is that the ABM condition typically involved (1) access to semantic and episodic knowledge about people relevant to the event and (2) the description of events related to the self.

Access to people knowledge. There is convincing neuropsychological evidence that anterior temporal lobe regions are involved in the representation of semantic knowledge about objects, concepts, people, facts, and the meanings of words (Kopelman \& Kapur, 2001; Patterson \& Hodges, 2000). For example, the main neuropsychologicalcharacteristic of patients with semantic dementia, who present with focal atrophy of anterior and inferior temporal areas, is a progressive loss of semantic knowledge in both verbal and nonverbal domains that typically affects all categories of information (Bozeat, Lambon Ralph, Patterson, Garrard, \& Hodges, 2000; Hodges \& K. S. Graham, 2001; Hodges, N. Graham, \& Patterson, 1995; Lambon Ralph, McClelland, Patterson, Galton, \& Hodges, 2001; Rogers et al., in press). It is not clear, however, how semantic memory is organized within the temporal lobes and whether the neural architecture adheres to psychological distinctions between semantic categories (e.g., between concepts of living vs. nonliving things or knowledge of people vs. knowledge of objects). The full range of issues pertaining to this topic is too broad and too complicated to deal with in detail here, and readers are directed to a recent book on the topic by Forde and Humphreys (2002); here, we focus only on the possibility that differences in our patterns of activation between autobiographical and semantic memory may reflect a neuroanatomical distinction between knowledge of people and knowledge of general semantics.

In several neuropsychological case studies, the right temporal lobe has been implicated as a critical locus for knowledge of people (Ellis, Young, \& Critchley, 1989; Evans, Heggs, Antoun, \& Hodges, 1995; Gentileschi, Sperber, \& Spinnler, 1999; Hanley, Young, \& Pearson, 1989; Kitchener \& Hodges, 1999), although other studies suggest that left-sided damage can also result in similar, albeit milder, deficits (Eslinger, 1998; Hodges \& K. S. Graham, 1998). In a recent investigation, Thompson, Graham, Patterson, and Hodges (2003) assessed 12 patients with semantic dementia on a battery of tests requiring access to semantic knowledge about either familiar objects or famous people. Patients with predominantly left temporal lobe atrophy performed better, although by no means normally, on knowledge of people than did those with predominantly right or bilateral temporal lobe involvement. By contrast, whereas patients with right temporal lobe damage showed a trend toward better performance on objects, especially on tests of naming, bilateral damage was associated with more severe impairments than unilateral atrophy, regardless of side of involvement. These findings 


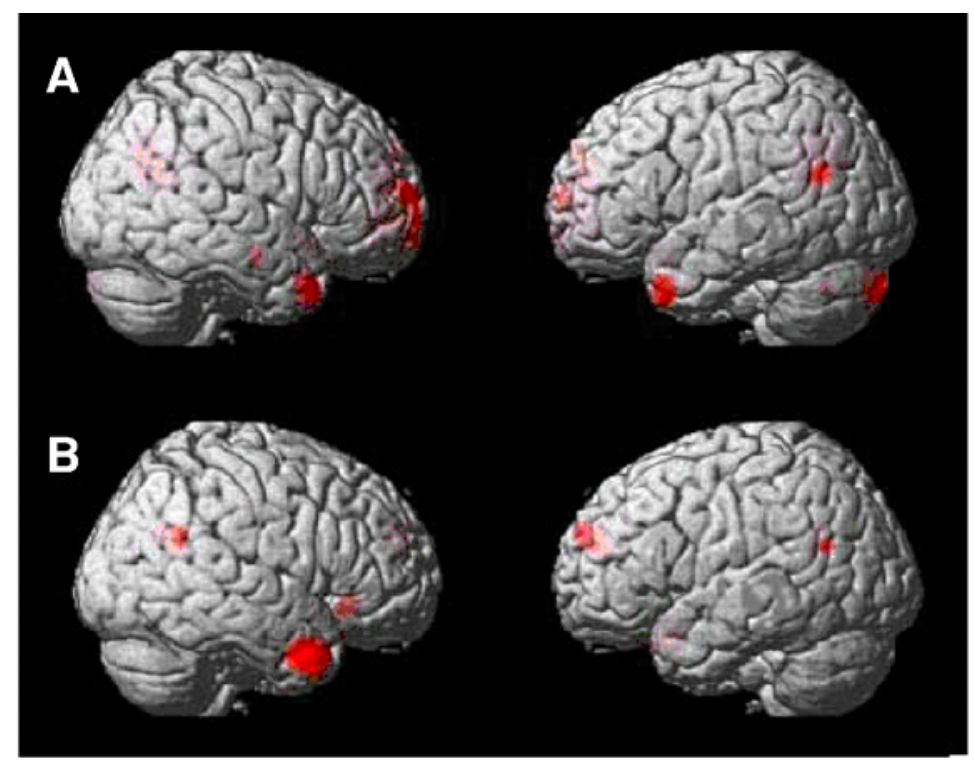

Figure 7. Regions of significant regional cerebral blood flow change when (A) general semantic knowledge was subtracted from people knowledge ( $P$ SEM) and (B) general semantic knowledge was subtracted from famous events knowledge (FEV - SEM), superimposed on an average 3-D-rendered MRI scan.

were interpreted as evidence that semantic memory for both people and objects is dependent on a bilaterally distributed network within the temporal lobes (see also Lambon Ralph et al., 2001) but with the right temporal lobe being more involved in knowledge about people (Thompson et al., 2003).

There is some support for this view from functional neuroimaging: Although Gorno-Tempini and colleagues (Gorno-Tempini et al., 2000; Gorno-Tempini \& Price, 2001; Gorno-Tempini et al., 1998) have reported predominantly left-sided anterior temporal lobe activations during same-different matching tasks for famous people and buildings, other imaging studies have found evidence of right or bilateral temporal involvement (Haist, Bowden Gore, \& Mao, 2001; Kapur, Friston, Young, Frith, \& Frackowiak, 1995; Leveroni et al., 2000; Sergent, Ohta, \& MacDonald, 1992; Simons, Graham, Owen, Patterson, \& Hodges, 2001). Simons et al. investigated the neural correlates of knowledge about objects compared with of faces (among other variables) using a recognition memory paradigm (see also Kelley et al., 1998). With a combination of familiar and unfamiliar stimuli, regions more active for objects than for faces were located in bilateral posterior temporal areas, whereas faces minus objects preferentially activated the right hemisphere, including the temporal pole (BA 38) and inferior temporal gyrus (BA 20). In fact, the patterns reported by Simons et al. are remarkably similar to those documented in the analysis from this study, in which we contrasted ABM - SEM and SEM - ABM. Given these results, a possible explanation for our finding that ABM - SEM resulted in activation of a right tempo- ral region is that autobiographical recall typically provokes activation of knowledge about people as well as general semantic facts about the concept.

\section{Analysis 3: Autobiographical \\ Memory-Process or Store?}

In Study 3, in addition to our ABM and SEM conditions, the subjects produced information about both famous and personally relevant people as well as about famous events from the past. We matched these conditions for retrieval demand to the other conditions by asking the subjects to select an appropriate target stimulus from nonspecific labels (e.g., president and bombing). On the basis of previous literature, we predicted that the contrasts of people and/or famous events to general semantic retrieval would result in patterns of activity similar to those seen for $A B M$ - SEM. Given that activations within the temporal lobe were of primary relevance, region-of-interest (ROI) analyses were carried out in the temporal lobes bilaterally. The ROI, defined via MRIcro (Rorden \& Brett, 2001) by an experienced neurologistblind to the PET data, encompassed the inferior and middle temporal gyri and the ventral surface of the temporal lobe (posterior limit: $y=-72$ ).

Blood Flow Changes. Our first contrast between the two people (P) conditions (FP and PP) and the SEM condition (P - SEM) yielded activation bilaterally in the anterior temporal lobe, although only the activation on the left survived correction [left BA 22/38, $p$ (corr) $=.01$; see Figure 7A]. In addition, there was a strong activation in the right posterior cingulate gyrus (BA 23) which was significant $[p$ (corr) $=.001]$. The opposite contrast, SEM $-\mathrm{P}$, 
Table 3

Stereotaxic Coordinates of Significant rCBF Change in the Temporal Lobes (Region-of-Interest Analysis) When People Knowledge Was Contrasted With General Semantic Knowledge

\begin{tabular}{|c|c|c|c|c|c|}
\hline \multirow[b]{2}{*}{ Region } & \multicolumn{4}{|c|}{$\underline{\text { Stereotaxic Coordinates }}$} & \multirow[b]{2}{*}{$z$ score } \\
\hline & $\mathrm{BA}$ & $x$ & $y$ & $z$ & \\
\hline \multicolumn{6}{|c|}{ People - Semantic } \\
\hline \multicolumn{6}{|l|}{ Left hemisphere } \\
\hline Temporal pole & 38 & -46 & 12 & -29 & $4.5^{*}$ \\
\hline Superior temporal cortex & 22 & -51 & -57 & 23 & 3.9 \\
\hline \multicolumn{6}{|l|}{ Right hemisphere } \\
\hline Temporal pole & 38 & 44 & 12 & -29 & 3.9 \\
\hline \multicolumn{6}{|c|}{ Semantic - People } \\
\hline \multicolumn{6}{|l|}{ Left hemisphere } \\
\hline Posterior inferior temporal cortex & 37 & -59 & -53 & -11 & $6.1^{*}$ \\
\hline Inferior temporal cortex & 20 & -51 & -26 & -22 & $4.5^{*}$ \\
\hline \multicolumn{6}{|l|}{ Right hemisphere } \\
\hline Middle temporal cortex & 20 & 59 & -36 & -15 & $4.2^{*}$ \\
\hline Posterior inferior temporal cortex & 37 & 65 & -53 & -10 & $4.1 *$ \\
\hline
\end{tabular}

$*$ Survives $p=.05$ corrected for multiple comparisons.

recruited the inferior/middle temporal gyrus (BA 20) and the posterior inferior temporal cortex (BA 37) bilaterally, all of which were significant at a corrected level (see Table 3).

For FEV - SEM (see Figure 7B), there were no significant left hemisphere activations in the ROI analysis. There was, however, involvement of the right hemisphere, with the right middle temporal gyrus (BA 21) showing a strong trend toward corrected significance $[p$ (corr) $=.06$; see Table 4]. The opposite contrast, SEM - FEV, engaged only left posterior inferior temporal gyrus [BA 37; $p$ (corr) = .01 , with left middle temporal cortex (BA 21) yielding significant activity at an uncorrected level (see Table 4).

Comment. The more specific analyses of Study 3 revealed that the retrieval of information about famous events and, to a lesser extent, about famous people, in contrast with recall of general semantic information, resulted in anterior temporal lobe activations that were bilateral in the case of people and right sided for famous events. The right BA 21 and 38 activations in both the FEV - SEM contrast $[\{48,8,-29\}$ and $\{51,3,-27\}]$ and the P - SEM comparison $\{44,12,-29\}$ were very similar to the reported ABM - SEM activations from Analysis 1 \{50, 4, $-36\}$. This was not true of the left-sided middle temporal area $\{-46,12,-29\}$ from the $\mathrm{P}-$ SEM comparison, which was more anterior than the region identified in Analysis $2\{-51,-22,-16\}$.

There was, therefore, significant overlap between the results obtained from the FEV - SEM and P - SEM contrasts and that reported in Analysis 1 for ABM - SEM: All these conditions-people, famous events, and autobiographical memory-were more likely to result in involvement of anterior temporal regions, especially on the right, whereas retrieval of information about people also resulted in increases in $\mathrm{rCBF}$ in the anterior left middle temporal gryus. Given these findings, it seems reasonable to hypothesize that the activations revealed in our first analysis, when ABM was contrasted with SEM, may reflect the retrieval of information about people in the ABM condition and/or the need to recall information about events per se, rather than activation of a separate psychological and neuroanatomical autobiographical memory system.

Table 4

Stereotaxic Coordinates of Significant rCBF Change

in the Temporal Lobes (Region-of-Interest Analysis) When

Event Knowledge Was Contrasted With General Semantic Knowledge

\begin{tabular}{|c|c|c|c|c|c|c|}
\hline \multirow[b]{2}{*}{ Region } & & \multicolumn{4}{|c|}{ Stereotaxic Coordinates } & \multirow[b]{2}{*}{$z$ score } \\
\hline & & BA & $x$ & $y$ & $z$ & \\
\hline \multicolumn{7}{|c|}{ Famous Events - Semantic } \\
\hline \multicolumn{7}{|l|}{ Right hemisphere } \\
\hline Middle temporal cortex & & 21 & 48 & 8 & -29 & 4.0 \\
\hline Middle temporal cortex & & 21 & 51 & 3 & -27 & 4.0 \\
\hline \multicolumn{7}{|c|}{ Semantic - Famous Events } \\
\hline \multicolumn{7}{|l|}{ Left hemisphere } \\
\hline Posterior inferior tempo & cortex & 37 & -61 & -53 & -12 & $5.2 *$ \\
\hline Middle temporal cortex & & 21 & -53 & -30 & -22 & 3.6 \\
\hline
\end{tabular}

*Survives $p=.05$ corrected for multiple comparisons. 


\section{DISCUSSION}

Previous functional neuroimaging studies of autobiographical memory have predominantly suggested involvement of a left-sided frontal and temporal network of brain regions (Maguire, 2001). By contrast, neuropsychological studies in patients with deficits in autobiographicalmemory imply a critical role of right temporal structures (Calabrese et al., 1996; Kopelman et al., 1999), or at least that significant deficits arise only from bilateral damage to anterior temporal lobe regions (Eslinger, 1998; Graham \& Hodges, 1997). There are two possible explanations for this discrepancy in the literature: (1) Neuropsychological studies do not facilitate separation of the relevant contributions of autobiographical and semantic memory to remote memory tests (Kopelman \& Kapur, 2001); and/or (2) neuroimaging studies have frequently failed to tap aspects of autobiographical retrieval that might be dependent on right temporal regions (Conway et al., 2002). In this study, we used a novel, neuropsychologically informed imaging paradigm to investigate the neural basis of LTM, especially autobiographical memory, and found significant involvement of bilateral medial frontal and temporal neocortical regions in autobiographical retrieval (in keeping with findings from the neuropsychologicalliterature). Recall of semantic facts - in contrast with autobiographical memory (and memory for people and events) —engaged a predominantly left-sided network involving posterior temporal cortex (BA 37) and prefrontal cortex (BA 45/46), although there were similar right-sided activations in these regions which failed to reach significance at a corrected level.

\section{Autobiographical Specificity and the Role of the Right Temporal Lobe}

The novel design of our paradigm provided the subjects with sufficient time for true autobiographical recall and allowed us to contrast this type of memory retrieval with a suitably matched control condition (e.g., recall of remote semantic knowledge). In the introduction, we argued (in concert with Conway et al., 2002) that the paradigms used previously in the neuroimaging literature on autobiographical memory did not require detailed autobiographical retrieval. In accordance with this proposal, we found less involvement of right temporal lobe regions in our task when the amount of time available for retrieval, and, consequently, the specificity of the memories, was reduced toward the timing parameters in Conway et al. (1999). A similar explanation can be proposed for the verification tasks used by Maguire and colleagues, in which subjects only have to respond yes/no to a presented statement (Maguire, 2001; Maguire, Henson, et al., 2001; Maguire \& Mummery, 1999; Maguire et al., 2000); this method is unlikely to require retrieval of a recollective event and, instead, presumably taps only more general levels of autobiographical knowledge.

The further analyses carried out on the data from Study 3 help explain why the retrieval of autobiographical mem- ory may activate both temporal lobes during imaging and why Maguire and Mummery's (1999) original memory network analysis failed to find evidence of a significant role of right temporal regions. Comparison of our people (FP and PP) and event (FEV) conditions with general semantic memory (SEM) revealed increased $\mathrm{rCBF}$ in the middle temporal gyrus (bilaterally for people and predominantly in the right for famous events). These activations were very similar to those obtained in our original analysis (ABM - SEM) and indicate that the retrieval of autobiographical memories may engage a semantic system that is bilaterally distributed within the temporal lobes, rather than a neuroanatomically separate LTM store for remote personal events.

Study 3 also hints at a more explicit account of what autobiographicalspecificity might mean (see Figure 6 and Conway et al., 2002). Since the autobiographical activations in the right, but not the left, temporal lobe are in a region similar to those recruited when subjects produce information about famous people and events, this implies that autobiographical specificity may actually refer to the retrieval of knowledge, later in the recall period, about people participating in the event. For example, subjects performing our autobiographical memory cue-word task may access an event in the following way: thinking about a life time period ("when I was at university") before identifying a general event ("running the bouncy castle competition during freshman orientation week") and eventually producing details about a specific episodic memory ("taking a friend John to the hospital after he broke his leg on the bouncy castle"). Note that we are not suggesting here that the left temporal lobe represents only general semantic knowledge and the right only knowledge of famous people and events. Our present analyses revealed bilateral involvement of temporal regions in all tasks, including the retrieval of general semantic and people knowledge as well as that of autobiographical memories, a finding which is highly consistent with neuropsychological studies of these domains of LTM in which bilateral lesions are typically considered to be the most detrimental (Conway \& Fthenaki, 2000; Kopelman \& Kapur, 2001). There does seem, however, to be some predisposition for knowledge of famous people to be more dependent on the right temporal lobe (Ellis et al., 1989; Evans et al., 1995; Leveroni et al., 2000; Thompson et al., 2003).

Neuropsychologicalpredictions. Our functional neuroimaging studies provide new predictions to be tested in neuropsychological populations. For example, patients with autobiographical memory deficits after temporal lobe lesions should show impairments in the retrieval of knowledge of famous people and famous events. Kopelman et al. (1999) report just such a finding: Their patients with right-sided temporal lobe damage were particularly impaired on autobiographical memory, but also showed deficits on a test of famous events, especially when the images involved perception of famous faces. Kitchener and Hodges (1999; see also De Renzi et al., 1987) reported a patient with semantic dementia and predominantly right 
temporal lobe damage who, in keeping with our imaging findings from Study 3, was severely impaired on tests requiring knowledge of famous people and events (see also Thompson et al., 2003). Discrepant from our hypothesis, however, was the fact that the patient was able to retrieve autobiographical memories both in semistructured interviews and on a test similar to that used in our study. Kitchener and Hodges proposed that, in circumstances in which there is damage to a very discrete semantic store, such as knowledge of famous people, autobiographicalmemories can be retrieved by supporting activation from other multimodal representations (Rubin \& Greenberg, 1998). As was noted by Kopelman and Kapur (2001), therefore, the distinction between autobiographical and semantic memory is not clear-cut, and further neuropsychological studies are necessary in order to characterize the relationship between these two domains of memory.

Categorical organization of semantic memory? Up to this point, we have concentrated predominantly on the results of the contrast between autobiographical and semantic memory and on explaining the discrepancies between functional neuroimaging and neuropsychological studies of autobiographicalmemory. In fact, our findingsat least with respect to the temporal lobes-seem equally informative about the neuroanatomy of semantic memory, given our hypothesis that the patterns seen during autobiographical retrieval may actually reflect semantic processing. Whereas retrieval of information about famous people and famous events (in contrast with general semantic recall) recruited anterior temporal regions, our general semantic tasks typically engaged bilateral (predominantly left) and quite posterior regions of temporal cortex. Of course, functional activation contrasts reveal only relative degrees of involvement in different conditions, and, therefore, this pair of findings does not rule out a role for anterior temporal regions in general semantic knowledge. For several reasons, however, it is puzzling that our general semantic activations were so posterior.

First, patients with semantic dementia, who present with a progressive loss of semantic knowledge, typically do not have significant atrophy in these more posterior regions of temporal lobes. A functional neuroimaging study by Mummery et al. (1999) sheds some light on this topic. The pattern of $\mathrm{rCBF}$ seen during performance on a semantic decision task in 4 patients with semantic dementia was contrasted with that of 6 control subjects who participated in the same experiment. The patients showed significant reduction in activity, relative to controls, in the left posterior inferior temporal gyrus (BA 37), despite voxel-based morphometry revealing no significant structural damage to this region. This result suggests that there is reduced input from structurally damaged anterior regions to structurally intact posterior areas, which subsequently fail to function normally in semantic dementia. The BA 37 region that was hypometabolic in the patients in Mummery et al.'s (1999) study $\{-54,-52,-10\}$ is very close to the area that was maximally active in our SEM - ABM contrast $\{-52,-49,-14\}$.
This finding leads to the second puzzle with respect to the function of BA 37. Patients with focal damage to BA 37, although anomic, do not show the profound semantic deficits seen in neurological disorders that affect more anterior temporal neocortex (Lambon Ralph, 2001, unpublished data). It has been proposed, therefore, that this region may play a role in the computation of phonological representations (Moore \& Price, 1999) rather than in the retrieval of semantic memory per se. In line with this proposal, Mummery et al. (1999) interpreted their pattern in semantic dementia as evidence that reduced input from anterior temporal regions results in underfunctioning of BA 37, and consequently profound anomia, which is typically the most consistent and severe behavioral deficit seen in semantic dementia. Our data suggest an alternative hypothesis: Assuming that the degree of lexical activation is similar in both our autobiographical and our semantic conditions - and there is no reason to think otherwiseour findings imply that posterior temporal regions may be involved in semantic processes beyond naming.

Lee et al. (2002) reported an analysis of the semantic conditions included in Study 2, in which subjects were asked to retrieve either perceptual or nonperceptual information about concepts of living and nonliving things. Although there was no support for the view that semantic knowledge was organized by category - that is, there were no differences between the living and the nonliving contrasts-the type of attribute (e.g., perceptual vs. nonperceptual) retrieved during the feature-listing task modulated activity within the left temporal lobe. A significant increase in $\mathrm{rCBF}$ was observed in the left posterior inferior temporal cortex [BA $37,\{-51,-68,-2\}]$ during the production of perceptual attributes, whereas significant increases in activity were seen in the left middle temporal cortex (BA 21) and right fusiform cortex (BA 37) during the retrieval of nonperceptual features. This result, when considered alongside the findings reported here, suggests that BA 37 may play a role in representing perceptual semantic knowledge.

Lee et al.'s (2002) findings, and the results documented here, hint at another factor that might be important in understanding patterns of performance in neuropsychological and neuroimaging studies of semantic memory. When the subjects were asked to retrieve more specific or unique information about concepts (e.g., facts about people or nonperceptual information about objects), there was more involvement of anterior regions within the temporal lobe, whereas recall of more generic facts, which are common to many concepts (e.g., perceptual features), resulted in activation of more posterior temporal areas (typically bilaterally). Gorno-Tempini et al. (2001) comment on a similar finding, noting that functional neuroimaging studies of semantic memory typically demonstrate activity in anterolateral regions of middle and inferior temporal gyri (BA 20/21) when more specific semantic knowledge is required in order to complete the test (e.g., when subjects categorize objects, as in Devlin et al., 2000, or match words according to associations or semantic features, as in Mummery, Patterson, Hodges, Wise, \& Price, 1998, and Van- 
denberghe, Price, Wise, Josephs, \& Frackowiak, 1996). A plausible, albeit unproven, explanation for these patterns is that semantic memory is not organized categorically, but, instead, that general or shared semantic features, especially perceptual characteristics, are represented in posterior temporal regions close to perceptual processing areas, whereas more unique or distinct information depends more on anterior temporal regions.

\section{Role of Frontal Regions \\ in Autobiographical and Semantic Memory}

Finally, although our study has concentrated on the role of temporal lobe regions in autobiographical and semantic memory, it is interesting to consider the distinct frontal activations that were revealed by our contrasts. Maguire and Mummery (1999) found that rCBF was increased in the left medial frontal cortex, as well as in the temporal pole and temporoparietal junction, when personal memories (autobiographical events and knowledge of personally relevant people) were directly contrasted with nonpersonal memories (famous events and knowledge of famous people). Similarly, we found that both right and left medial frontal cortex (BA 9/10) were recruited during the recall of autobiographicalepisodes. This pattern may reflect the processing of information related to self: Craik et al. (1999) tested whether asymmetries in memory encoding versus retrieval could be due to the need for reference to the self in episodic retrieval. In different conditions of a PET study, subjects were asked to judge trait adjectives according to how well the words described themselves (self), how well they described someone else (other), how socially desirable the traits were (general), and how many syllables the trait word contained (syllable). Self-related encoding (contrasting self to other, general, and syllable combined) resulted in left frontal activations, including left and right medial frontal cortex (BA 10 and 9) and inferior frontal gyrus (BA 45).

Medial prefrontal cortex has also been implicated in tasks that require monitoring and/or the attribution of mental states, such as analysis of eye gaze and tasks requiring theory of mind (Calder et al., 2002; Castelli, Happe, Frith, \& Frith, 2000; Fletcher, Happe, Frith, Baker, \& Dolan, 1995; Gallagher et al., 2000). Notably, theory-of-mind tasks also seem to engage areas in the temporal pole generally close to the amgydala (Baron-Cohen et al., 1999; Castelli et al., 2000), as well as the temporoparietal junction (a pattern very similar to that reported by Maguire \& Mummery, 1999, and Maguire et al., 2000). The need for reference to the self in autobiographicalmemory tasks, particularly with respect to the intentions and goals of subjects in the event, may thus also engage medial prefrontal cortex. These regions have also been shown to be activated during rest but deactivated during cognitive tasks (Raichle et al., 2001; Shulman et al., 1997). In the introduction, we proposed that rest is likely to be a poor control for autobiographical retrieval because subjects are likely to engage in autobiographicallike processing (Christoff et al., 2001). Perhaps these medial frontal regions may be deactivated during cognitive tasks that require the suspension of spontaneous thought processes related to self or monitoring of one's emotional state (Raichle, 1998; Shulman et al., 1997).

Turning to the frontal activations revealed during our general semantic task, in accordance with much of the literature, recall of general semantic facts about concepts (in comparison with recall in the other conditions) resulted in increased $\mathrm{rCBF}$ in the left ventrolateral prefrontal gyrus (BA 45). This activation was bilateral, although the increase in blood flow between the two contrasts in the area activated in the right hemisphere (BA 46) did not reach statistical significance. This activation presumably reflects the need for the subject to select and organize semantic information for the task, rather than being associated with semantic processing per se (Thompson-Schill, D'Esposito, Aguirre, \& Farah, 1997).

\section{REFERENCES}

Andreasen, N. C., O'Leary, D. S., Cizadlo, T., Arndt, S., Rezai, K., Watkins, G. L., Ponto, L. L., \& Hichwa, R. D. (1995). Remembering the past: Two facets of episodic memory explored with positron emission tomography.American Journal of Psychiatry, 152, 1576-1585.

Andreasen, N. C., O'Leary, D. S., Paradiso, S., Cizadlo, T., Arndt, S., Watkins, G. L., Ponto, L. L., \& Hichwa, R. D. (1999). The cerebellum plays a role in conscious episodic memory retrieval. Human Brain Mapping, 8, 226-234.

Baron-Cohen, S., Ring, H. A., Wheelwright, S., Bullmore, E. T., Brammer, M. J., Simmons, A., \& Williams, S. C. R. (1999). Social intelligence in the normal and autistic brain: An fMRI study. European Journal of Neuroscience, 11, 1891-1898.

Bozeat, S., Lambon Ralph, M. A., Patterson, K., Garrard, P., \& Hodges, J. R. (2000). Non-verbal semantic impairment in semantic dementia. Neuropsychologia, 38, 1207-1215.

Brett, M., Bloomfield, P., Brooks, D., Stein, J. F., \& Grasby, P. M. (1999). Scan order effects in PET activation studies are caused by motion artefact. NeuroImage, 9, S56.

Burgess, N., Maguire, E. A., Spiers, H. J., \& O' Keefe, J. (2001). A temporoparietal and prefrontal network for retrieving the spatial context of life-like events. NeuroImage, 14, 439-453.

Calabrese, P., Markowitsch, H. J., Durwen, H. F., Widlizek, H., Haupts, H., Holinka, B., \& Gehlen, W. (1996). Right temporofrontal cortex as the critical locus for the ecphory of old episodic memory. Journal of Neurology, Neurosurgery, \& Psychiatry, 61, 304-310.

Calder, A. J., Lawrence, A. D., Keane, J., Scott, S. K., Owen, A. M., Christoffels, I., \& Young, A. W. (2002). Reading the mind from eye gaze. Neuropsychologia, 40, 1129-1138.

Castelli, F., Happe, F., Frith, U., \& Frith, C. (2000). Movement and mind: A functional imaging study of perception and interpretation of complex intentional movement patterns. Neurolmage, 12, 314-325.

Christoff, K., Ream, J. M., \& Gabrieli,J. D. E. (2001). Mental processes during rest. Cognitive Neuroscience Society Abstracts (p. 72).

Conway, M. A. (2001). Sensory-perceptual episodic memory and its context: Autobiographicalmemory. Philosophical Transactions of the Royal Society of London, Series B: Biological Sciences, 356, 1375-1384.

Conway, M. A., \& FThenaki, A. (2000). Disruption and loss of autobiographical memory. In L. S. Cermak (Ed.), Handbook of neuropsychology, 2nd edition: Memory and its disorders (pp. 281-312). Amsterdam: Elsevier.

Conway, M. A., \& Pleydell-Pearce, C. W. (2000). The construction of autobiographical memories in the self-memory system. Psychological Review, 107, 261-288.

Conway, M. A., Pleydell-Pearce,C. W., \& Whitecross, S. E. (2001). The neuroanatomy of autobiographical memory: A slow cortical potential study of autobiographical memory retrieval. Journal of Memory \& Language, 45, 493-524.

Conway, M. A., Pleydell-Pearce, C. W., Whitecross, S. [E.], \& 
Sharpe, H. (2002). Brain imaging autobiographical memory. Psychology of Learning \& Motivation: Advances in Research \& Theory, 41, 229-263.

Conway, M. A., Turk, D. J., Miller, S. L., Logan, J., Nebes, R. D., Meltzer, C. C., \& Becker, J. T. (1999). A positron emission tomography (PET) study of autobiographical memory retrieval. Memory, 7, 679-702.

Craik, F. I. M., Moroz, T. M., Moscovitch, M., Stuss, D. T., Winocur, G., Tulving, E., \& KAPUR, S. (1999). In search of the self: A positron emission tomography study. Psychological Science, 10, 26-34.

Crovitz, H. F., \& Schiffman, H. (1974). Frequency of episodic memories as a function of their age. Bulletin of the Psychonomic Society, 4, 517-518.

Dalla Barba, G., Cipolotti, L., \& Denes, G. (1990). Autobiographical memory loss and confabulation in Korsakoff's syndrome: A case report. Cortex, 26, 525-534.

De Renzi, E. Liotti, M., \& Nichelli, P. (1987). Semantic amnesia with preservation of autobiographic memory: A case report. Cortex, 23, 575-597.

Devlin, J. T., Russell, R. P., Davis, M. H., Price, C. J., Wilson, J., Moss, H. E., Matthews, P. M., \& Ty Ler, L. K. (2000). Susceptibilityinduced loss of signal: Comparing PET and fMRI on a semantic task. NeuroImage, 11, 589-600.

Ellis, A. W., Young, A. W., \& Critchley, E. M. R. (1989). Loss of memory for people following temporal lobe damage. Brain, 112, 1469-1483.

ESLINGER, P. J. (1998). Autobiographical memory after temporal and frontal lobe lesions. Neurocase, 4, 481-495.

Evans, J. J., Breen, E. K., Antoun, N., \& Hodges, J. R. (1996). Focal retrograde amnesia for autobiographical events following cerebral vasculitis: A connectionist account. Neurocase, 2, 1-11.

Evans, J. J., Heggs, A. J., Antoun, N., \& Hodges, J. R. (1995). Progressive prosopagnosia associated with selective right temporal lobe atrophy: A new syndrome? Brain, 118, 1-13.

Fink, G. R., Markowitsch, H. J., Reinkemeier, M., Bruckbauer, T., Kessler, J., \& HEISS, W.-D. (1996). Cerebral representation of one's own past: Neural networks involved in autobiographical memory. Journal of Neuroscience, 16, 4275-4282.

Fletcher, P. C., Happe, F., Frith, U., Baker, S., \& Dolan, R. J. (1995). Other minds in the brain: A functional imaging study of "theory of mind" in story comprehension. Cognition, 57, 109-128.

Fletcher, P. C., \& Henson, R. N. (2001). Frontal lobes and human memory: Insights from functional neuroimaging. Brain, 124, 849-881.

Forde, E. M. E., \& Humphreys, G. W. (2002). Category specificity in brain and mind. Hove, U.K.: Psychology Press.

Gallagher, H. L., Happe, F., Brunswick, N., Fletcher, P. C., Frith, U., \& Frith, C. D. (2000). Reading the mind in cartoons and stories: An f MRI study of theory of mind in verbal and nonverbal tasks. Neuropsychologia, 38, 11-21.

Garrard, P., Lambon Ralph, M. A., Hodges, J. R., \& Patterson, K. (2001). Prototypicality, distinctiveness, and intercorrelation: Analyses of the semantic attributes of living and nonliving concepts. Cognitive Neuropsychology, 18, 125-174.

Gentileschi, V., Sperber, S., \& Spinnler, H. (1999). Progressive defective recognition of familiar people. Neurocase, 5, 407-423.

Gorno-Tempini, M. L., Cipolotti, L., \& Price, C. J. (2000). Category differences in brain activation studies: Where do they come from? Philosophical Transactions of the Royal Society of London, Series B: Biological Sciences, 267, 1253-1258.

Gorno-Tempini, M. L., \& Price, C. J. (2001). Identification of famous faces and buildings: A functional neuroimaging study of semantically unique items. Brain, 124, 2087-2097.

Gorno-Tempini, M. L., Price, C. J., Josephs, O., Vandenberghe, R, Cappa, S. F., Kapur, N., Frackowiak, R. S., \& Tempini, M. L. (1998). The neural systems sustaining face and proper-name processing. Brain, 121, 2103-2118.

Gorno-Tempini, M. L., Wenman, R., Price, C., Rudge, P., \& Cipolotti, L. (2001). Identification without naming: A functional neuroimaging study of an anomic patient. Journal of Neurology, Neurosurgery, \& Psychiatry, 70, 397-400.

Graham, K. S., \& Hodges, J. R. (1997). Differentiating the roles of the hippocampal complex and the neocortex in LTM storage: Evidence from the study of semantic dementia and Alzheimer's disease. Neuropsychology, 11, 77-89.

Graham, K. S., Pratt, K. H., \& Hodges, J. R. (1998). A reverse temporal gradient for public events in a single case of semantic dementia. Neurocase, 4, 461-470.

Haist, F., Bowden Gore, J., \& MAO, H. (2001). Consolidation of human memory over decades revealed by functional magnetic resonance imaging. Nature Neuroscience, 4, 1139-1145.

Hanley, J. R., Young, A. W., \& Pearson, N. A. (1989). Defective recognition of familiar people. Cognitive Neuropsychology, 6, 179-210.

HodGES, J. R., \& GRAHAM, K. S. (1998). A reversal of the temporal gradient for famous person knowledge in semantic dementia: Implications for the neural organisation of long-term memory. Neuropsychologia, 36, 803-825.

Hodges, J. R., \& Graham, K. S. (2001). Episodic memory: Insights from semantic dementia. Philosophical Transactions of the Royal Society of London, Series B: Biological Sciences, 356, 1423-1434.

Hodges, J. R., Graham, N., \& Patterson, K. (1995). Charting the progression in semantic dementia: Implications for the organisation of semantic memory. Memory, 3, 463-495.

Hokkanen, L., Launes, J., Vataja, R, Valanne, L., \& Iivanainen, M. (1995). Isolated retrograde amnesia for autobiographical material associated with acute left temporal lobe encephalitis. Psychological Medicine, 25, 203-208.

KAPUR, N. (2000). Focal retrograde amnesia and the attribution of causality: An exceptionally benign commentary. Cognitive Neuropsychology, 17, 623-637.

Kapur, N., Friston, K. J., Young, A., Frith, C. D., \& Frackowiak, R. S. (1995). Activation of human hippocampal formation during memory for faces: A PET study. Cortex, 31, 99-108.

Kapur, N., Young, A., Bateman, D., \& Kennedy, P. (1989). Focal retrograde amnesia: A long term clinical and neuropsychological followup. Cortex, 25, 387-402.

Kelley, W. M., Miezin, F. M., McDermott, K. B., Buckner, R. L., Raichle, M. E., Cohen, N. J., Ollinger, J. M., Akbudak, E., Conturo, T. E., Snyder, A. Z, \& Petersen, S. E. (1998). Hemispheric specialization in human dorsal frontal cortex and medial temporal lobe for verbal and nonverbal memory encoding. Neuron, 20, 927-936.

Kitchener, E., \& Hodges, J. R (1999). Impaired knowledge of famous people and events and intact autobiographical knowledge in a case of progressive right temporal lobe degeneration: Implications for the organization of remote memory. Cognitive Neuropsychology, 16, 589-607.

Kopelman, M. D. (2000). Focal retrograde amnesia and the attribution of causality: An exceptionally critical review. Cognitive Neuropsychology, 17, 585-621.

Kopelman, M. D., \& Kapur, N. (2001). The loss of episodic memories in retrograde amnesia: Single-case and group studies. Philosophical Transactions of the Royal Society of London, Series B: Biological Sciences, 356, 1409-1421.

Kopelman, M. D., Stanhope, N., \& Kingsley, D. (1999). Retrograde amnesia in patients with diencephalic, temporal lobe or frontal lesions. Neuropsychologia, 37, 939-958.

Kroll, N. E. A., Markowitsch, H. J., Knight, R. T., \& von Cramon, D. Y. (1997). Retrieval of old memories: The temporofrontal hypothesis. Brain, 120, 1377-1399.

Lambon Ralph, M. A., McClelland, J. L., Patterson, K., Galton, C. J., \& Hodges, J. R. (2001). No right to speak? The relationship between object naming and semantic impairment: Neuropsychological evidence and a computational model. Journal of Cognitive Neuroscience, 13, 341-356.

Lee, A. C. H., Graham, K. S., Simons, J. S., Hodges, J. R., Owen, A. M., \& Patterson, K. (2002). Regional brain activations differ for semantic features but not categories. NeuroReport, 13, 1497-1501.

Leveroni, C. L., Seidenberg, M., Mayer, A. R., Mead, L. A., Binder, J. R., \& RAO, S. M. (2000). Neural systems underlying the 
recognition of familiar and newly learned faces. Journal of Neuroscience, 20, 878-886.

Levine, B., Black, S. E., Cabeza, R., Sinden, M., Mcintosh, A. R. Toth, J. P., Tulving, E., \& Stuss, D. T. (1998). Episodic memory and the self in a case of isolated retrograde amnesia. Brain, 121, 1951-1973.

Maguire, E. A. (2001). Neuroimaging studies of autobiographical event memory. Philosophical Transactions of the Royal Society of London, Series B: Biological Sciences, 356, 1441-1451.

Maguire, E. A., Henson, R. N. A., Mummery, C. J., \& Frith, C. D. (2001). Activity in prefrontal cortex, not hippocampus, varies parametrically with the increasing remoteness of memories. NeuroReport, 12, 441-444.

Maguire, E. A., \& Mummery, C. J. (1999). Differential modulation of a common memory retrieval network revealed by positron emission tomography. Hippocampus, 9, 54-61.

Maguire, E. A., Mummery, C. J., \& Büchel, C. (2000). Patterns of hippocampal-cortical interaction dissociate temporal lobe memory subsystems. Hippocampus, 10, 475-482.

Maguire, E. A., Vargha-Khadem, F., \& Mishrin, M. (2001). The effects of bilateral hippocampal damage on $\mathrm{AMRI}$ regional activations and interactions during memory retrieval. Brain, 124, 1156-1170.

Markowitsch, H. J., Calabrese, P., Fink, G. R., Durwen, H. F., Kessler, J., Harting, C., Konig, M., Mirzaian, E. B., Heiss, W. D., Heuser, L., \& GeHLen, W. (1997). Impaired episodic memory retrieval in a case of probable psychogenic amnesia. Psychiatry Research, 74, 119-126.

Markowitsch, H. J., Calabrese, P., Liess, J., Haupts, M., Durwen, H. F., \& GeHLEN, W. (1993). Retrograde amnesia after traumatic injury of the fronto-temporal cortex. Journal of Neurology, Neurosurgery, \& Psychiatry, 56, 988-992.

Markowitsch, H. J., Thiel, A., Reinkemeier, M., Kessler, J., Koy uncu, A., \& Heiss, W. D. (2000). Right amygdalar and temporofrontal activation during autobiographic, but not during fictitious memory retrieval. Behavioural Neurology, 12, 181-190.

Moore, C. J., \& Price, C. J. (1999). Three distinct ventral occipitotemporal regions for reading and object naming. NeuroImage, 10, 181-192.

Mummery, C. J., Patterson, K., Hodges, J. R., Wise, R. J. S., \& Price, C. J. (1998). Functional neuroanatomy of the semantic system: Divisible by what? Journal of Cognitive Neuroscience, 10, 766-777.

Mummery, C. J., Patterson, K., Wise, R. J. S., Vandenberghe, R, Price, C. J., \& Hodges, J. R. (1999). Disrupted temporal lobe connections in semantic dementia. Brain, 122, 61-73.

Murre, J. M. J., Graham, K. S., \& Hodges, J. R. (2001). Semantic dementia: Relevance to connectionist models of long-term memory. Brain, 124, 647-675.

NADEL, L., \& Moscovitch, M. (1997). Memory consolidation, retrograde amnesia and the hippocampal complex. Current Opinion in Neurobiology, 7, 217-227.

Nadel, L., Samsonovich, A., Ryan, L., \& Moscovitch, M. (2000). Multiple trace theory of human memory: Computational, neuroimaging, and neuropsychological results. Hippocampus, 10, 352-368.

Nestor, P. J., Graham, K. S., Bozeat, S., Simons, J. S., \& Hodges, J. R. (2002). Memory consolidation and the hippocampus: Further evidence from the study of autobiographical memory in semantic dementia and the frontal variant of frontotemporal dementia. Neuropsychologia, 40, 633-654.

NIKI, K., \& LUO, J. (2002). An fMRI study on the time-limited role of the medial temporal lobe in long-term topographical autobiographic memory. Journal of Cognitive Neuroscience, 14, 500-507.

Patterson, K., \& Hodges, J. R. (2000). Semantic dementia: One window on the structure and organisation of semantic memory. In L. Cer- mak (Ed.), Revised handbook of neuropsychology: Memory and its disorders (pp. 313-335). Amsterdam: Elsevier.

Raichle, M. E. (1998). The neural correlates of consciousness: An analysis of cognitive skill learning. Philosophical Transactions of the Royal Society of London: Series B, 353, 1889-1901.

Raichle, M. E., MacLeod, A. M., Snyder, A. Z, Powers, W. J., GusNARD, D. A., \& Shulman, G. L. (2001). Inaugural article: A default model of brain function. Proceedings of the National Academy of Sciences, 98, 676-682.

Rogers, T. T., Lambon Ralph, M. A., Garrard, P., Bozeat, S., MCClelland, J., Hodges, J. R., \& Patterson, K. (in press). Structure and deterioration of semantic memory. Psychological Review.

Rorden, C., \& BRETT, M. (2001). Stereotaxic display of brain lesions. Behavioural Neurology, 12, 191-200.

Rubin, D. C., \& GreenberG, D. L. (1998). Visual memory deficit amnesia: A distinct amnesic presentation and etiology. Proceedings of the National Academy of Sciences, 95, 5413-5416.

Ryan, L., Nadel, L., Keil, K., Putnam, K., Schnyer, D., Trouard, T., \& Moscovitch, M. (2001). Hippocampal complex and retrieval of recent and very remote autobiographical memories: Evidence from functional magnetic resonance imaging in neurologically intact people. Hippocampus, 11, 707-714.

Sergent, J., Ohta, S., \& MacDonald, B. (1992). Functional neuroanatomy of face and object processing: A positron emission tomography study. Brain, 115, 15-36.

Shulman, G. L., Fiez, J. A., Corbetta, M., Buckner, R. L., Miezin, F. M., Raichle, M. E., \& Petersen, S. E. (1997). Common blood flow changes across visual tasks: II. Decreases in cerebral cortex. Journal of Cognitive Neuroscience, 9, 648-663.

Silbersweig, D., Stern, E., Frith, C., Cahill, C., Schnorr, L., Grootoonk, S., Spinks, T., Clark, J., Frackowiak, R, \& Jones, T. (1993). Detection of thirty-second cognitive activations in single subjects with positron emission tomography: A new low-dose $\mathrm{H}_{2}{ }^{15} \mathrm{O}$ regional cerebral blood flow three-dimensional imaging technique. Journal of Cerebral Blood Flow \& Metabolism, 13, 617-629.

Simons, J. S., Graham, K. S., Owen, A. M., Patterson, K., \& Hodges, J. R. (2001). Perceptual and semantic components of memory for objects and faces: A PET study. Journal of Cognitive Neuroscience, 13, 430-443.

SQuire, L. R. (1992). Memory and the hippocampus: A synthesis from findings with rats, monkeys, and humans. Psychological Review, 99, 195-231.

TAlairach, J., \& Tournoux, P. (1988). Co-planar stereotaxic atlas of the human brain. New York: Thieme Medical.

Thompson, S. A., Graham, K. S., Patterson, K., \& Hodges, J. R. (2003). Left and right temporal lobe contributions to object and person knowledge: Evidence from semantic dementia. Manuscript submitted for publication.

Thompson-Schill, S. L., D’Esposito, M., Aguirre, G. K., \& Farah, M. J. (1997). Role of left inferior prefrontal cortex in retrieval of semantic knowledge: A reevaluation. Proceedings of the National Academy of Sciences, 94, 14792-14797.

Tyler, L. K., Moss, H. E., Durrant-Peatfield, M. R., \& Levy, J. P. (2000). Conceptual structure and the structure of concepts: A distributed account of category-specific deficits. Brain \& Language, 75, 195-231.

Vandenberghe, R., Price, C., Wise, R., Josephs, O., \& Frackowiak, R. S. (1996). Functional anatomy of a common semantic system for words and pictures. Nature, 383, 254-256.

(Manuscript received February 11, 2003; revision accepted for publication August 12, 2003.) 